\title{
5 Das Kurienzeremoniell des Anno Santo von 1575
}

\begin{abstract}
Insigne quidem ac nobile eius officii specimen editur vidimus diebus nostris a Sanctissimo Domino nostro Gregorio decimotertio Romano Pontefice (haec modo libere effari liceat, cum iam ipso defuncto, nulla possit esse adulationis suspicio) cuius incomparabile plane studium in iuvandis pauperibus, non solum (ut de medicis taceam) omnibus honesto praesertim loco natis, Romae agentibus, sed \& longe positis, toto plane Christiano orbe spectatum fuit. ${ }^{577}$
\end{abstract}

Während des Ghislieri-Pontifikates Pius‘ V. hatten sich die Widerlegungsarbeiten gegen die Magdeburger Zenturiatoren an die kurialen Auseinandersetzungen mit den res Germaniae und der ab 1571 einberufenen Indexkongregation angepasst. Die Annäherung dieser beiden Arbeitsbereiche der Kurie waren allerdings von den stadträumlichen Bedingungen Roms isoliert. Solange diese Arbeiten ausserhalb der Mauern des Apostolischen Palastes - vornehmlich innerhalb stadtrömischer Bruderschaften - keine Anerkennung fanden, konnte kein allgemeingültiger Anspruch über eine Kirchengeschichte erhoben werden.

Mit der Papstwahl Ugo Boncompagnis als setzte schliesslich ein Prozess der allmählichen Einbindung des stadtrömischen Wandels in die kurienzeremoniellen Ausstattungen des Palazzo Apostolico ein. Die Fresken Giorgio Vasaris in der Sala Regia können als Anfang dieser Entwicklung betrachtet werden. Das Kurienzeremoniell begann sich schrittweise den urbanen Dimensionen anzunehmen, um dadurch kurienzeremonielle Feiern auch im Stadtraum selbst durchführen zu können. Damit wurden auch die Expurgationsarbeiten der Kurie in liturgischer Hinsicht an den Stadtraum Roms angenähert, wodurch die Normkollision verschiedener Riten angemessen gelöst werden konnte. Im folgenden Teil der Untersuchung sollte daher der Frage nachgegangen werden, wie Cesare Baronio aus der 1575 päpstlich anerkannten Kongregation des Oratoriums in die kurialen Arbeitsbereiche gegen die Magdeburger Zenturiatoren gelangen konnte. Eine zentrale, aber bislang kaum berücksichtigte Grundlage zur Einbindung des Oratorianers in der Kurie bildete die Überführung des Kurienzeremoniells in den römischen Stadtraum. Diese Überführung erreichte im Jubeljahr 1575 ihren Höhepunkt.

Jüngst schlug Giuseppe Antonio Guazzelli vor, die Annales Ecclesiastici anhand ausgewählter „Baronian elements in Baronio“ zu untersuchen. Guazzelli machte damit darauf aufmerksam, dass Cesare Baronios eigene Gedanken grundlegend von einer Kollektividee, wie Kirchengeschichte nach Trient geschrieben werden sollte, zu unterscheiden sind. ${ }^{578}$ Allerdings blieb die Betrachtung der Annales bislang ausschliesslich auf einen Einfluss Filippo Neris und der Kongregation des Oratoriums beschränkt. Dadurch konnten Baronios eigene Gedanken in seinen Annales nur geringfügig aufgedeckt werden. Solche „baronianischen Elemente“ in den Annales

577 Ann. Ecc., II, S. 184.

578 Guazzelli 2012b, S. 71.

Ә Open Access. (C) 2022 Filip Malesevic, publiziert von De Gruyter. (c) BY-NC-ND Dieses Werk ist lizenziert unter einer Creative Commons Namensnennung - Nicht-kommerziell - Keine Bearbeitung 4.0 International Lizenz. https://doi.org/10.1515/9783110741117-006 
lassen sich aber, wie im Folgenden ausgeführt werden soll, nicht nur in Einzelfällen, sondern im Gesamtwerk Baronios erkennen. Einen der wichtigsten Eigengedanken, die Baronio mit seinem Werk vermittelt wollte, war derjenige der Ecclesia semper eadem. Mit diesem Gedanken einer ,immer gleichbleibenden Kirche“ vertrat Baronio jedoch nicht die Idee, dass die Romana Ecclesia in ihrer Geschichte keinen Veränderungen ausgesetzt gewesen sei. Im Gegenteil, seine Annales Ecclesiastici erzählen die Geschichte einer Kirche, die von einem ständigen Wandel über die Jahrhunderte hinweg geprägt war. Für Baronio ging dieser Wandel aber mit der Veränderlichkeit von Riten und deren Liturgie an sich einher. Deshalb verstand er die Ecclesia als sichtbare Hülle, innerhalb der sich verschiedene Riten liturgisch vollziehen konnten. Dieser rituelle Vollzug konnte aber auch die sichtbare Hülle selbst umformen. Der Begriff der Ecclesia fiel für den Oratorianer Cesare Baronio somit mit der zeremoniell-ästhetischen Ausstattung des Kirchenbaus zusammen, weshalb in den folgenden Ausführungen auch auf den im Wandel begriffenen Kirchenbau des späten Cinquecento eingegangen werden soll.

\title{
5.1 Die Eröffnung der Kirchengeschichte als Ankunft des Gotteswortes
}

Als der Mailänder Bischof Carlo Borromeo Rom anlässlich des bevorstehenden anno santo besuchte, verfasste er ein an die Gläubigen seiner Diözese adressiertes Pastoralschreiben. In diesem fasste er die Bestimmungen des Boncompagni-Papstes für die Feierlichkeiten des Jubeljahres 1575 folgendermassen zusammen:

\begin{abstract}
Ne vi dovete solamente conte(n)tar di andar à Roma, à visitare quelle chiese, \& reliquie de Santi, ma à questo dovete congiungnere vera \& perfetta penitenza, di modo che facciate questo viaggio in gratia di Dio, \& con tal mortificatione della carne, \& sensi vostri, che serva anco per la satisfattione delli vostri peccati [...] \& con santa sobrietà, astinenza, \& modestia Christiana in ogni vostra conversatione, fate che il viaggio sia accompagnata da mortificatione, \& gastigio d'ogni vostra sensualità. ${ }^{579}$
\end{abstract}

Mit seiner Betonung der Kasteiung des eigenen Körpers bezog sich Borromeo auf die während des Jubeljahres stattfindenden Prozessionen flagellanter Bruderschaften, wie die der Gonfalone-Bruderschaft. Der Mailänder Bischof betrachtete diese Bussprozessionen als essentielles Element einer spirituellen Wiederbelebung der christlichen communitas. Die Nachahmung der Geisselung Christi durch eine mortificazione del corpo, wie sie von flagellanten Bruderschaften Roms aufgeführt wurde, wird in Borromeos Pastoralbrief als sichtbarer Ausdruck einer perfetta penitenza hervorgehoben. Diese „makellose Busse“, welche die Ecclesia militans auszeichnet,

579 Borromeo, A tutti i fideli della città et diocese nostra, Salute nel Signore (10 settembre 1574). Zit. n. Wisch 1990, S. 96. Eine englische Übersetzung findet sich in Martin, Roma Sancta, S. 226. 
färbe die Strassen der Stadt Roms mit einer maravigliosa abondanza di sangue. ${ }^{580}$ Carlo Borromeos Brief zeugt daher nicht nur von einer sichtbaren Manifestation der Romana Ecclesia, die bereits im Vorfeld des Jubeljahres 1575 deutlich spürbar wurde. Das Schreiben gilt auch als ein wichtiges Zeugnis dafür, dass der Apostolische Palast gegenüber der Stadt Rom als eigentlicher Ort, an dem die nötigen Pastoralwerke während des gesamten Jubeljahres auszuführen waren, betrachtet werden sollte. Bei den zeremoniellen Vorbereitungen der Kurie auf das anno santo begann der päpstliche Herrschaftsapparat dessen Stellenwert für den göttlichen Heilserlass neu auszulegen. Carlo Borromeos Pastoralbrief vom September 1574 bildete einen wichtigen Stein im grösseren Mosaik des kurialen Selbstverständnisses während des BoncompagniPontifikates.

Ein avviso vom 15. Januar 1574 berichtet, dass Gregor XIII. die Kardinäle dazu aufrief ,a vivere santamente venendo l'anno santo, per dare essempi a forestieri di tante nationi che corrono in Roma“. ${ }^{581} \mathrm{Im}$ Jubeljahr war nämlich eine Heiligkeit cum hodie praesentium temporum haeresibus et calamitatibus enthalten, die erst mit der Pflege einzelner Kirchen und deren Schmuck (ut basilicae et ornetur) betont werden konnte, deren Aufsicht den Kardinälen Giacomo Savelli und Stanislaus Hosius anvertraut wurde. ${ }^{582}$ Dass die Pflege römischer Kirchen im Hinblick auf das Jubeljahr 1575 dem vicarius urbis Savelli übertragen wurde, scheint nicht überraschend zu sein, denn der Kardinalvikar Roms war für die städtische Raumorganisation ex officio zuständig. Überraschender scheint hingegen der Umstand, dass der Boncompagni-Papst den ab 1574 zum Grosspönitentiar berufenen Stanislaus Hosius mit derselben Aufgabe betraute. Die Forschung richtete bei der Rekonstruktion des Jubeljahres 1575 ihre Auf-

580 Riera, Historia utilissima et diletissima, c. 76r-v: „[...] era ancho una gran moltitudine di battuti, i quali tal modo percuotevano le lor proprie spalle, che i colpi si potevano sentire lunghi ducento passi con tal maravigliosa abondanza di sangue, che tutta la Città ne fu tinta, \& bagnata, in memoria di colui, che (mercè de' nostri peccati) crudelissimame(n)te da Giudei fu flagellato“.

581 BAV, Urb. lat. 1044, f. 3v. Dieser Aufruf war eine innerhalb des weitgespannteren Rahmens von Voraussetzung, welche eine gelungene Durchführung des Jubeljahres überhaupt erst ermöglichen sollten. Vgl. zu diesem Rahmen Maffei, Degli annali di Gregorio XIII, I, S. 153: „fare in modo bene edificate della romana conversazione se ne tornino alle case loro salde nella religione [...] e bene affette verso la Sene Apostolica“. $\mathrm{Zu}$ den sozialen und wirtschaftlichen Rahmenbedingungen innerhalb des städtischen Raumes vgl. Delumeau 1957/59, Bd. 2, S. 606.

582 Santori, Diario concistoriale, in: Tacchi Venturi 1903, S. 217-218. Vgl. hierzu dann auch das avviso vom 27. Februar 1574 in BAV, Urb. lat. 1044, f. 39v. Zentraler Bestandteil der Heiligkeit des giubileo war dessen eigentliche etymologische Namensgebung, die dieser alle 25 Jahre stattfindenden Feier ihren Sinn zuwies, indem alle 100 Jahre nach Christi Geburt eine Plenarindulgenz durch den päpstlichen Akt der Segnung erteilt wurde. Dies geht aufBonifaz VIII. zurück. Vgl. diesbez. Frugoni 1999, S. 3-32; Kat. Roma 2000, S. 51-55; Paravicini Bagliani 1997, S. 168-183; Ragionieri 1997, S. 216-223. Die Etymologie des Begriffs giubileo geht auf das hebräische Leviticum 25, den eigentlichen „Kontext der Heiligkeit“, zurück und beruft sich auf das Hebräische yôbêl: Caquot 1997, S. 16-31. Die entsprechenden Bibellstellen aus dem Alten Testament sind folgende: Lev 25, 831; Dt 16, 13; Ex 23, 10-11. 
merksamkeit vorwiegend auf die Zusammenarbeit zwischen Savelli und dem Sekretär des Sacro Collegio, Silvio Antoniano. Der Stellenwert, den die Penitenzieria Apostolica für das anno santo einnahm, blieb dabei unberücksichtigt. Unter der Leitung des Ermländer Bischofs Hosius entwickelte die Apostolische Pönitentiarie aber ein grundlegendes Neuverständnis vom sacramentum poenitentiae und gliederte dieses erfolgreich in die zeremoniellen Feierlichkeiten zum anno santo ein. ${ }^{583}$

Die Wahl Hosius zum penitenziere maggiore hatte zur Folge, dass eine christologisch-dogmatische Auslegung des Gotteswortes innerhalb der römischen Kurie kontroverstheologisch integriert werden konnte. Die mit dieser Dogmatik verbundene Theologie der Ablasspraxis sollte den städtischen Raum in eine Landschaft des Heilsgeschehens verwandeln. Im Zentrum dieser Landschaft des Heils stand das mysterium der Geburt Christi. Diese Veränderung des römischen Stadtraumes zu einem heilgeschichtlichen Zentrum des göttlichen Sündenerlasses konnte nur mit Hilfe der Einbindung Carlo Borromeos innerhalb der Kurie bewerkstelligt werden. Da aber Borromeo sich seiner Aufgabe als Mailänder Bischof bewusst war und demzufolge das Tridentiner Residenzdekret streng zu befolgen gedachte, setzte er seinen vertrauenswürdigsten Agenten in Rom, Bernardino Carniglia, in die Pönitentiarie ein. ${ }^{584}$ Anlässlich der dritten Provinzialsynode in Mailand legte Carlo Borromeo 1573 seine Instructiones praedicatoris verbi Dei nieder. Diese Instruktionen stellten seitens der Kurie das Vorbild dar, wie die Theologie der Fleischwerdung

583 Über die Wahl des Ermländer Bischofs zum penitenziere maggiore berichtet Bernardino Carniglia in einem Briefschreiben an Borromeo vom 9. September 1573 in BAM, F 128inf., 31r. Vor Hosius trat Giovanni Aldobrandini in der Nachfolge Carlo Borromeos als penitenziere maggiore 1573 ein, der gleichzeitig auch die Brevenpräfektur innehatte. Zusammen mit Borromeo, Paleotti und Burali reorganisierte Aldobrandini die Pönitentiarie neu. Vgl. hierzu insbes. Carlo Borromeos Dekret an Aldobrandini vom 21. September 1569 in APA, Acta Cardinalium, I, f. 10v-11r. Vgl. dazu Borromeo 2009, S. 131. Ein Briefschreiben Carniglias aus der Biblioteca Ambrosiana berichtet ferner von der Besetzung des Amtes des penitenziere maggiore nach Aldobrandinis Tod: BAM, F 128inf., f. 360r-v. Welche Massnahmen seitens der Kurie $1574 \mathrm{zu}$ den Vorbereitungen des Jubeljahres getroffen wurden, lässt sich aus den avvisi in BAV, Urb. lat. 1044, f. 204r, 234r, 310r, 434v, 39v, 204r, 214v, 279v, $262 r$, 274r, 338r, rekonstruieren. Diese Rekonstruktion war bereits Gegenstand in Bonadonna Russo 1975, S. 371-385. Antoniano hinterliess eine in der Biblioteca Vaticana aufbewahrte Aufzeichnung seiner Beobachtungen zu religiösen, liturgischen sowie organisatorischen Elementen des Jubeljahres in BAV, Vat. lat. 6204, f. 190r-191v, deren Adressat unbekannt bleibt. Jedoch lässt die memoria vermuten, dass sie für Savelli verfasst sein musste.

584 Carniglia war zwischen 1573 und 1576 Sekretär der Bischofskongregation. Aus APA, Acta Cardinalium, I, f. 31v-32v geht hervor, dass Carniglia das Amt des sigillatore innerhalb der Pönitentiarie bekleidete. Zu diesem Amt, das Pius V. mit der Bulle In omnibus rebus einsetzte, vgl. insbes. Saraco 2012, S. 17. Dieses Amt kann als Vorgänger zum Amt des Archivars betrachtet werden, welches allerdings erst 1818 mit der Promulgation des Regolamento per la Segretatia ed Archivio della Sacra Penitenzieria kreiert wurde. Hinsichtlich der Figur Carniglias vgl. DBI 20, 1977, S. 488-490. Für Carniglias Tätigkeit als Sekretär der Bischofskongregation vgl. dann das Dokument in ASV, Sacra Congregatio Episcoporum et Regularium, Collectanea, II, f. $2 r-v$. 
Gottes im Jubeljahr sichtbar zur Schau gestellt werden konnte. Borromeos Instructiones sind aber nicht ausschliesslich als eine Anweisungen zur Predigt zu lesen. In diesen zeichnet der Mailänder Bischof und Kardinal ein bestimmtes Modell des episcopus, wie es auch bereits die Konzilsväter im Dekret zur Residenzpflicht vorlegten und nach dessen Vorbild sich jeder Diözesanbischof orientieren sollte. ${ }^{585}$ Die beiden Diözesansynoden Borromeos von 1573 und 1576 fanden in einem wichtigen Zeitraum statt, in dem auch die Kurie die Theologie des mysterium der Geburt Christi in eine sichtbare Manifestation des christlichen Heilsgeschehens umwandelte.

Noch zu Zeiten des Ghislieri-Papstes Pius V. stand die Abendmahlstheologie im Zentrum des mysterium fidei, weshalb das Mysterium der christlichen Heilserlangung allein im Apostolischen Palast sichtbar artikuliert wurde. Die römische Stadtgesellschaft und der urbane Raum hatten daran nur minimalen Anteil, was sich auch am Mangel päpstlicher Eingriffe in den Stadtraum dieser Zeit ablesen lässt. ${ }^{586}$ Carlo Borromeos Instructiones sind das Produkt einer Reihe weiterer Diözesansynoden, zu deren Anlass das Tridentiner Dekret vom 17. Juni 1546 zur Predigt neu ausgelegt wurde. Die Drucklegung der Akten dieser Partikularsynoden im Italien des Cinquecento musste allerdings bis in die 1580er Jahre warten. Der Bischof von Bologna Gabriele Paleotti hatte sich beispielsweise in seiner 1586 veröffentlichten Instruttione explizit auf das neunte Kapitel der seconda regola des heiligen Francesco d'Assisi gestützt und diese entsprechend für seine Diözesansynode ausgebaut. ${ }^{587}$ Bor-

585 Motta 2005, S. 117; O’Malley 1993, S. 139-157; Giombi 1997, S. 69-80.

586 Die avvisi 1568 und 1569 berichten über einen deutlichen Mangel an päpstlichen Urbanisierungsprojekten: in BAV, Urb. lat. 1041, f. 123r, 148v, 307r. Dies war durch den finanziellen Zustand der Ecclesia in summa fisci nostri inopia bedingt: Pastor 1893-1933, Bd. 8, S. 72-76; Simoncini 2008, Bd. 2, S. 223-248. Giorgio Vasaris Biographie Daniele da Volterras in der zweiten Edition seiner Vite enthält bezüglich der Ausmalung der Sala Regia eine interessante Passage, die womöglich aus der finanziellen Krise des Ghislieri-Pontifikates 1568 erklärt werden kann. Vgl. Vasari, Vite, VII, S. 62: „[...] il cardinale di Carpi cercò che fusse da Sua Santità data a finire a Daniello la detta sala dei Re; ma non si dilettando quel papa di pitture, rispose esser molto meglio fortificare Roma, che spendere in dipingere“. Zum Festungsbau unter Pius V. vgl. dann die Stelle aus dem anonym gebliebenen Discorso sopra la fortificazione del Castel S. Angelo e del Borgo di Roma l'anno 1568 in BAM, R 121sup., f. 257r-260r. Womöglich könnte sich hinter diesem Traktat der Ingenieur aus Neapel verbergen, zumal er sich 1568 in Rom aufhielt und im darauffolgenden Jahr seinen eigenen Discorso di fortificationi del sig. Carlo Theti napolitano herausbrachte. Hierzu insbes. Mollo 2008, S. 83-132; Robotti 2005, S. 299-311.

587 Prodi 1959/67, Bd. 2, S. 75-136. Zum Tridentiner Dekret Vgl. COD, S. 645: [...] annuntiando eis cum brevitate et facilitate sermonis vitia, quae eos declinare, et virtutes, quas sectari oporteat, ut poenam aeternam evadere et coelestem gloriam consequi valeant. Das Zitat entspricht wörtlich der regola seconda der Franziskaner: Seraphicae legislationis textus originales, S. 44. Es ist durchaus denkbar, dass hauptsächlich der Franziskaner Cornelio Musso für eine solche explizite Einbindung franziskanischer Predigtvorstellungen in das Tridentiner Dekret verantwortlich war. Vgl. bereits Jedin 1933, S. 207-275; Cantini 1941, S. 146-174, 424-463; Bartman 1945, S. 247-276; Odoardi 1948, S. 223-242, 450-478; idem 1949, S. 36-71. Musso hatte ebenfalls dann als Bischof von Bitonto eine Provinzialsynode im Jahr 1579 organisiert. 
romeo scheint sich aber nicht an den Tridentiner Bestimmungen zur Predigt orientiert zu haben, denn er bezieht sich nicht direkt auf das Konzilsdekret. Gemäss Borromeo sollten Predigten folgende Bereiche ansprechen: die Sünden, die Momente des Sündigens, die Tugenden, die sakramentale Verwaltungspraxis und die weiteren Praktiken der kirchlichen Sündenvergebung. Der Prediger sollte als uditor Christianus die Gläubigen immer wieder zurück auf die „Strasse des Herrn“ bringen und sie durch eine rastlos vom Bösen angegriffene Welt führen. ${ }^{588}$ Carlo Borromeos Instructiones weisen daher ein Bild des Predigers (oratore) als vir bonus, dicendi peritus auf. Gemäss dieser Vorstellung des Predigers ist dieser aber nicht für den rituellen Vollzug der Theologie des Gotteswortes (logos) als mysterium zuständig. In seiner Vita des Mailänder Bischofs legte Agostino Valier entsprechend ein Bild Borromeos vor, der kniend das Evangelium vorliest. Valier hatte damit Carlo Borromeo bewusst in seiner Nachahmung des Kirchenlehrers Thomas von Aquin dargestellt. Mit diesem biographischen Bildnis des Mailänder Bischofs wollte Valier zeigen, wie sich in der Diözesanverwaltung Borromeos das gesprochene Wort dem Akt des Schreibens anglich. Die Predigten Borromeos hatten aber nicht zum Ziel, gegenüber seinem Publikum das mysterium des Gotteswortes zu enthüllen. ${ }^{589}$

Carlo Borromeos Instruktionen zur Predigt des Gotteswortes haben somit nur oberflächlich die Theologie und das mysterium fedei der Fleischwerdung Gottes behandelt. Ihre sichtbare Artikulation sollten sie demgemäss im Bild des Predigers und allen voran in der Predigt selbst erhalten. Es ist aber zu beachten, dass Borromeo sich in seinen Instructiones erstmals mit der Frage, wie das Tridentiner Predigtwesen in Bezug auf das bischöfliche praecipuum munus erweitert werden könne, auseinandersetzte. Ähnlich wie Paleotti verstand Borromeo den predigenden Bischof in seinem Akt der oratio. Die späteren Biographien des Mailänder Bischofs allen voran die Valiers, die des Barnabiten und Bischofs von Novarra Carlo Bascapè sowie die des Jesuiten Antonio Possevino - berichten von Borromeos drei- oder gar viermal an einem Tag gehaltenen Predigten, auch wenn Borromeo selbst gegenüber der öffentlichen Predigt abgeneigt war und eine schwache Stimme gehabt haben

588 AEM, I, S. 394: [...] videbit concionator diligenter, quanta, et quam summa difficultate ei proponitur, qui in tanta, tamquam perpetua et mundi et Satanae oppugnatione fidelium animas ad viam Domini revocare contendit. Vgl. auch Borromeo, Homiliae, II, S. 15: [...] ut homines beluarum more vitam ducentes, ad evangelicam vitam tam numerose converteret. Borromeos Ansicht der Predigt ist, wie O'Malley bereits beobachten konnte, eine von derjenigen Predigtauslegung unterschiedliche Interpretation, welche noch während der ersten Hälfte des Cinquecento dominant war. Vgl. dazu O’Malley 1979, S. 355-373; McGinness 1982, S. 355-370; Fumaroli 1994.

589 Valier, Vita Caroli Borromei, S. 48: Et ita orationem cum lectione, Thomas Aquinatem sanctissimorum virorum doctissimum imitatus, coniungebat sex annos antequam ex hac vita migraret, ut nunquam nisi genusflexus sacrosanctum illum librum perlegert. Die Grenzen des Predigtverständnisses Borromeos sind auch in AEM, I, S. 215 ersichtlich: Deinde se qui praedicationis munus aggreditur, ministrum esse, per quem verbum Dei ab ipso divini Spiritus fonte ducitur ad fidelium animas divinitus irrigandas. Vgl. ähnlich Borromeo, Homiliae, I, S. 108-109; ibid., II, S. 23-24, 70. 
soll. ${ }^{590}$ Die bis zum 18. Jahrhundert unveröffentlicht gebliebenen Homiliae Borromeos legen nichtsdestotrotz eine Vorstellung vom mysterium des Gotteswortes dar, wie es der Mailänder Bischof verstand. Auch wenn Borromeos theologisches Wissen gemäss François de Sales’ Einschätzung eher „bescheiden“ war, genügte ihm dieses für den Aufbau seiner Predigten. ${ }^{591}$ O’Malley konnte anhand einer Auswahl der Predigten Borromeos darlegen, dass Borromeos theologisches Verständnis des mysterium fidei des Gotteswortes eng mit den zeremoniellen Rahmenbedingungen, die der Mailänder Bischof auch in seinen Homiliae ansprach, verbunden waren. Borromeos Predigten sind daher nicht unabhängig von den liturgisch-zeremoniellen Bedingungen der Ecclesia und deren sichtbarem Verständnis zu betrachten. Die anlässlich der Bestattungsfeier für die spanische Königin gehaltene Predigt wurde beispielsweise durch ein im Mailänder Dom errichtetes ephemeres Katafalk unterstützt. Um seiner Predigt den Charakter einer Leichenrede verleihen zu können, bezog sich Borromeo immer wieder bewusst auf diesen Katafalk. ${ }^{592}$ Carlo Borromeos Predigten sind deshalb stets als feierlicher genus demonstrativum zu betrachten, da in diesem mit Hilfe des genus deliberativum einzelne Bibelstellen panegyrisch eingerahmt werden. Das verbum Dei wurde damit stets von den res umhüllt, ohne dabei jemals auf den eigentlichen Inhalt der Predigt einzugehen. ${ }^{593}$ Dem verbum Dei wird demgemäss eine Mittlerfunktion zugesprochen. Dieses sollte den Gläubigen auf den bereits erwähnten „Pfad des Herrn“ leiten. Das mysterium der Fleischwerdung Gottes, die letzten Endes die göttliche Heilserlangung versprach und im Kreuzes- und Messopfertod Christi eingelöst wurde, wurde aber dadurch nicht sichtbar manifestiert. Protestantische Theologen konnten daher den Predigtvollzug des Mysteriums der Fleischwerdung immer anfechten, indem sie die liturgisch-zeremonielle Inszenierung der Predigt selbst kritisierten.

Mit ihrem am 11. November 1563 verabschiedeten Reformdekret beabsichtigten die Tridentiner Konzilsväter die rudimenta fidei, welche jede Predigt auszeichneten, auf der Grundlage des Evangeliums festzulegen. Der Sprechakt des Predigers sollte mit dem Predigtinhalt zusammenfallen. Erst dadurch konnte sichergestellt werden, dass die veritas fidei Kraft des Bischofsamtes und des Klerus in der Ausübung der

590 Valier, Vita Caroli Borromei, S. 10, 29; Bascapè, De vita et rebus gestis, S. 329, 333; Possevino, Discorsi, S. 45-46.

591 De Sales hielt dies in einem Brief an André Frémont vom 5. Oktober 1604 fest, in Denis, Oeuvres, XII, S. 301: „Quant à la doctrine, il faut qu'elle soit suffisante, et n'est pas requis qu'elle soit excellente [...] et en nostre age, le bienheureux cardinal Borromé n'avoit de science que bien fort mediocrement: toutefois il faisoit merveilles“. Vgl. hierzu auch ibid., S. 189; Broutin 1953, S. 282299, 380-398; O’Malley 1997, S. 62.

592 Giussano, De vita et rebus gestis, Sp. 591-592; O’Malley 1997, S. 62-63; Pigozzi 1990, S. $128-$ 140; eadem 2010, S. 143-150; Leotti 2010, S. 151-161.

593 Fumaroli 1994, S. 116-152. Vgl. auch Borromeos Institutiones ad universum seminarii regimen pertinentes in AEM, III, Sp. S. 859-878, wo zwischen der oratio scolastico more und einer Predigt tamquam theologia positiva unterschieden wird. 
pastoralen Seelsorge angemessen an die Gläubigen vermittelt wurde. ${ }^{594}$ Dort wo Carlo Borromeos Instructiones mit seinen Homiliae übereinstimmen, lässt sich ein zentrales Bedürfnis Borromeos feststellen, die pastorale Seelsorge von ihrer mündlichen Vermittlung in den Schriftgebrauch zu überführen. Mit Carlo Borromeo setzte damit ein zentraler kultureller Prozess ein, in dem die mündliche Predigt verschriftlicht wurde. Die Ordnung dieser Predigten, die einem entsprechenden officium zugewiesen waren, sollte dieselben in einen schriftlichen corpus der artes praedicandi übertragen. Deshalb blieb die Predigt für den Mailänder Bischof stets dem usus ecclesiae verpflichtet. Borromeo war wenig daran interessiert, sich mit der Frage, wie die Rahmenbedingungen der Ecclesia selbst die Predigtpraxis zu Gunsten einer Offenbarung des Mysteriums der Fleischwerdung Gottes bestimmten, auseinanderzusetzen. Eine Antwort auf diese Frage sollte hauptsächlich der ab 1571 zum Bischof von Verona berufene Kardinal Agostino Valier geben. In seiner Schrift De cautione adhibenda in edendis libris erinnerte sich Valier später noch daran, wie ihm Carlo Borromeo unmittelbar nach seiner Wahl zum Bischof von Verona diese Aufgabe aufgetragen habe. Darin erklärte Valier auch, dass er aus diesem Grund mit dem Jesuitenkardinal Francesco Adorno zusammenzuarbeiten begonnen habe, denn schliesslich bedurfte es bei dieser Aufgabe einer theologisch fundierten Exegese des vierten Buches von Augustinus' De doctrina christiana. ${ }^{595}$ Valier und Adorno arbeiteten an einer Überführung der artes praedicandi in eine rhetorica ecclesiastica und schufen grundlegende Voraussetzungen dafür, wie im späten Cinquecento die

594 Vgl. supra Kap. 1.3; COD, S. 669-670; Rusconi 1996, S. 18-24; idem 1981, S. 995-1006.

595 Valier, De cautione adhibenda in edendis libris, (Cipriani 2009) S. 194-294, 229-230: Mediolanum quinquies, septies etiam, dum Carolus Cardinalis nobilissimam illam ecclesiam administrabat, accessi. Cum primum ad pastorem illum egregium et ceterorum pastorum stimulum accessissem, aetatis nostrae excitatorem et magistrum egregium pastroralis artis. [...] Cumque illi hoc ipsum essem pliiticus, subridens dixit: Cur etiam pro tua pastorali cura et pro caritate tua in Ecclesiam Dei, praecepta quaedam dicendi non accommodas ad usum ecclesia? Cur ecclesiasticam non conscribis rhetoricam? Aderat Pater Franciscus Adormus, Societatis Iesu, quam antea nominavi, quem plurimi faciebat Cardinalis. [...] Hominem ab adolescentia in rhetorica facultate versatum, Philosophiae deditum, qui bonos libros legat, Theologiam etiam didicerat in publico Patavino Gymnasio ac theologia dogmata tractaverat [...] Quae Sanctus Augustinus in quarto libro De doctrina christiana scribit, satis esse ad rhetoricam ecclesiasticam constituendam et docendam Argumentum illud speciosum esse, sed vix cum laude tractari posse [...] Sed profecto verba Caroli Cardinalis Borromaei, cum Spiritu illum Sancto duci arbitrarer, tantam vim apud me habebant ut contradicere nequirem. Valier legte seine De adhibenda zeitgleich mit der Drucklegung der De controversiae Bellarminos nieder. Jedoch blieben sie bis 1719 unpubliziert. Ciprianis Edition bezieht sich auf eine in der Biblioteca Universitaria di Padova aufbewahrte Handschrift, die den Vermerk Veronae anno MDC4 trägt. Dieser Hinweis bezieht sich auf die Schriften Valiers, die zwischen 1589 und 1604 verfasst wurden. Vgl. hierzu jüngst dann auch Patrizi 2017, S. 251. Zur Beziehung zwischen Valier und dem Jesuiten Adorno vgl. den Briefwechsel in BAM, D 439inf., f. 3r-8v. Aus der Briefkorrespondenz Adornos mit Borromeo geht hervor, dass sich der Jesuit zwischen Mai und Juni 1573 in Rom aufhielt und somit als ein weiteres zentrales Bindeglied zwischen dem Mailänder Bischof und der Kurie betrachtet werden muss: BAM, F 127inf., f. 120r-v, 160r-v, $196 r$. 
Predigt allmählich zu ihrem Schriftcharakter fand. Allem voran war das Predigtwesen der Aufgabe, das Heilsversprechen Christi tatsächlich gewährleisten zu können, verpflichtet. Mit seiner 1574 gedruckten De rhetorica ecclesiastica legte Agostino Valier ein Werk vor, in welchem er die Kurie als alleinige Verwalterin der Sakramente erklärte. Damit entkoppelte Valier die Erfüllung des Heilsversprechens theologisch von einer bislang vom Dominikanerorden verwalteten Theologie des Abendmahls, die einen zentralen Platz in der Kirchenhistoriographie seit dem Ghislieri-Pontifikat Pius' V. einnahm. Dadurch gewann die rhetorica ecclesiastica zur theologischen Auslegung des Abendmahls an Abstand, wodurch die historia ecclesiastica als eine Geschichte des Heilsversprechens ab der Fleischwerdung Christi, das in der Entwicklung der Romana Ecclesia stets eingelöst wurde, verstanden werden konnte. ${ }^{596}$ Die ab der Drucklegung von Sisto da Sienas Bibliotheca sancta angestrebte Neuordnung kirchlicher Exegese anhand patristischer Textüberlieferungen ging somit in den Bereich der artes praedicandi über. Das Predigtwesen wurde von nun an in eine neue literarische Gattung der rhetorica ecclesiastica eingefügt, die Agostino Valier zu erforschen beabsichtigte. Die Disziplin der rhetorica ecclesiastica wies eine erstaunliche Fortführung der antiken Rhetorik auf, die Stanislaus Hosius in seinem 1558 erschienenem De expresso Dei verbo rekonstruierte. Der Ermländer Bischof und spätere Grosspönitentiar setzte sich darin mit der theologischen Bedeutung des Mysteriums der Fleischwerdung Gottes auseinander und versuchte den Nachweis zu erbringen, dass dessen Heilserfüllung in der kurialen Verwaltungspraxis der Sakramente gewährleistet werde. Gleich wie Hosius sah Agostino Valier in der Verwaltung der Sakramente eine Garantin des Glaubens, wie es im apostolischen Glaubensbekenntnis verkündet wurde. ${ }^{597}$ Carlo Borromeo stellte sich bei Valiers Arbeiten somit eine „Retorica non ristretta ad introduzione de' giovani, ma assoluta e perfetta per tutti quelli che nella Chiesa di Dio averanno desiderio di predicare con ordine e frutto“ vor. Deshalb unterbreitete der Jesuitenkardinal Francesco Adorno dem Bischof von Verona auch den Vorschlag, dass er in seinem Werk mehr ein modo di esplicar l'Evangelo anstreben solle. Seine De rhetorica ecclesiastica sollte sich damit über einen „stile un poco più culto, e castigato“ ausweisen. Adornos Verbesserungsvorschläge verhalfen Valier, der Figur des oratore cristiano bei den Überarbeitungen seiner De rhetorica ecclesiastica theologisch schärfere Konturen zu verleihen:

596 Zum Entstehungsprozess von Valies De rhetorica ecclesiastica vgl. seine ab 1571 mit Borromeo geführte und in der Biblioteca Ambrosiana aufbewahrte Briefkorrespondenz: BAM, F 85inf., f. 61r, 68v; BAM, F 86inf., f. 187r, 190r; BAM, F 124inf., f. 276r-277r, 289v; BAM, P 7inf., 149r, 225v. Eine Edition dieser Briefkorrespondenz legte bereits Tacchella 1972, S. 61-62, 100-102, vor.

597 Valier, De rhetorica ecclesiastica, I.11, S. 24-25: Et ut intelligat non omnia ad salutem pertinentia comprehendi expresso Dei verbo, legat Osii Cradinalis Vuarmiensis, doctissimi viri, pulcherrimum ea de re libellum. Credendos duodecim articulos qui in Sancto Apostolorum Symbolo continentur propo$n e t$, in quorum explicatione magnam copiam ei suggeret aureus liber qui proximis annis iussu Pii $V$ Pontificis Maximi est editus, Catechismus Romanus. 


\begin{abstract}
Il terzo ricordo, ch'è di trattar del modo di esplicar l'evangelio, e le scritture al popolo, sopra che, sebben nel terzo libro io aveva dato precetti universali, spero di dilatarmi in modo che V.R. resterà soddisfatta in parte; ma non cessi di far notar quelli, che giudicherebbe che fossero a proposito. Quando incominciai a scriver dubitai pian piano di non far del Teologo, e di non far una mezza somma, onde fosse giudicata la mia fatica superflua, e perciò lasciai questa parte delli sensi con li quali s'interpretano le scritture perché è stata trattata da molti. Ma spero di parlarne facilmente, ed inserir questa trattazione nell'opera, in modo che starò nelli termini; e similmente non sarà difficile parlar dell'uso che s'ha sempre tenuto nella Chiesa di applicar le figure del testamento vecchio al nuovo, e mi sforzerò di dar percetti più universali, più certi, e più facili che mi sia possibile. Quanto a quella parte onde desidera ch'io tratti delle figure oratorie, se ne potrà certo aggiungere alcune, ma non si potrà far menzione di tutte, scrivendo noi latino a persone che parlano volgare, ed appartenendo veramente la trattazione delle figure molto più al grammatico, ed all'orator del secolo; che all'orator cristiano. ${ }^{598}$
\end{abstract}

Eine typologische Gegenüberstellung von Figuren aus dem Alten und aus dem Neuen Testament reichte dafür nicht aus. Sowohl die rhetorica ecclesiastica als auch die Disziplin der oratoria sacra mussten selbst eine Exegese der Heiligen Schrift anhand der Patristik vorlegen können. Zusammen mit Carlo Borromeo arbeiteten Francesco Adorno und Agostino Valier an der Frage, wie sich in der rhetorica ecclesiastica die Verwaltungspraxis des Busssakraments mit der Kontroverstheologie der poenitentia vereinbaren liess. Agostino Valier zeigte in seiner De rhetorica ecclesiastica ein besonderes Spannungsverhältnis zwischen einer Busstheologie, wie sie die Apostolische Pönitentiarie vertrat, und der Verwaltung des Sakraments innerhalb des Predigtwesens auf. Damit zog der Bischof von Verona die theologischen Grenzlinien des foro intero. Diese Grenzen des römischen Gewissenstribunals konnten dadurch als real fassbare Grenzen der sakramentalen Verwaltungspraxis im urbanen Stadtraum Roms wahrgenommen werden. Das theologische Verständnis der Busse verhalf der Kurie, ihre Verwaltungspraxis dieses Sakraments mit der innerhalb römischer Bruderschaften vertretenen Predigtpraxis in Einklang zu bringen. Das forum internum wurde mittels der Verwaltung des Busssakraments im Kurienzeremoniell gegenüber dem römischen Stadtraum geöffnet. Der Apostolische Palast schlug damit sinnbildlich seine Gnadenpforten gegenüber der Stadtgesellschaft und den Pilgern auf.

Die Neuorganisation der Penitenzieria Apostolica, die im Ghislieri-Pontifikat Pius' V. ihren Höhepunkt erreichte, hatte eine solche Öffnung bereits angestrebt. In diesem Prozess wurde das sakramentale Verständnis der poenitentia anhand seiner Auslegung durch die Tridentiner Konzilsväter und ab 1566 auch anhand der Vorschriften im neuen Catechismus Romanus endgültig festgelegt. Die Neuordnung der Pönitentiarie verstand Pierre Chouët als ein „ufficio di piccoli favori del Papa che è cresciuto fino ad essere quasi l'unico dispensatore di privilegi, dispense e concessioni

598 Lettera del padre Francesco Adorno 1829, S. 11-18, 15-16. Zu den Vorstellungen Borromeos vgl. Logan 1996, S. 233-234; Patrizi 2017, S. 254-255. Für die sprachlichen Verbesserung hatte Borromeo Pietro Galesini vorgeschlagen: BAM, F 85inf., f. 61r, 68v; Tacchella 1972, S. 101. 
nel foro esterno“. ${ }^{599}$ Zusammen mit dem penitenziere maggiore wurde das Apostolische Gewissens- und Gnadentribunal zur alleinigen Instanz innerhalb der Kurie erklärt, mit welcher die päpstliche Dispenspraxis verwaltet wurde. Die Ämter innerhalb der Pönitentiarie wurden sodann gemäss dem katechetischen Verständnis der Busse in Bezug auf die bereits diskutierten casi riservati besetzt. ${ }^{600}$ In den casi riservati artikulierte sich nämlich die kirchliche Dispensautorität innerhalb des corpus fidelium. Die Praxis des päpstlichen Sündenerlasses konnte dadurch allein in persona Christi vollzogen und verstanden werden. Die Verwaltung des Busssakraments wurde damit allein den Bischöfen und dem collegio dei confessori der Penitenzieria Apostolica übergeben. Diese kuriale Verwaltung der Busse unterschied sich deutlich von einer pastoral geprägten Verwaltungsform der Beichte, für deren Abnahme die Priester zuständig waren. In Agostinos Valiers De rhetorica ecclestiastica ist somit eine Neuauslegung der artes praedicandi festzustellen, da Valier das Bischofsamt selbst ebenfalls neu verstand. Valiers Traktat ist als eine Ergänzung zum Tridentiner Dekret über die Residenzpflicht zu verstehen, denn in seiner De rhetorica ecclesiastica überführt Valier das Tridentiner Verständnis des episcopus aus dem Bereich des divinum praeceptum in den Verwaltungsbereich des ius divinum, das der römischen Kurie unterstand. ${ }^{601}$

Ferner verstand Agostino Valier das Sakrament der poenitentia als medicinam peccatorum und fasste damit die Busse im Zusammenhang mit der kurialen Praxis des Ablasses und der Sündenvergabe, wie sie vom neuen Catechismus vorgeschrieben wurde. Erst mit dieser katechetischen Interpretation des Sakraments konnte eine Verwaltungspraxis der Busse angestrebt werden, wie sie im Kurienzeremoniell dann rituell zu vollziehen war. Das Sakrament stellt für Valier in seinem Traktat eine „Verlängerung des himmlischen Reiches“ dar, die den durch die Sünde verursachten inneren „Schmerz“ (dolor) eines jeden Gläubigen zu heilen im Stande sei. Diese Auslegung stimmt mit jener Vorschrift im Catechismus Romanus überein, mit

599 DThC 12, Sp. 1143; Rodríguez 2009, S. 138-139.

600 Vgl. supra Kap. 1.4.

601 Zur Tridentiner Debatte um das ius divinum in Bezug auf die Residenzpflicht vgl. Jedin 1966, Bd. 2, S. 398-413; idem 1949-1975, Bd. 4/1, S. 114-115. Die Akten zu den konziliaren Debatten finden sich in CT, VIII, S. 403-463. Vgl. auch das endgültige Reformdekret vom 15. Juli 1563, das zusammen mit dem Dekret über das sacramentum ordinis erlassen wurde und das im Gegensatz $\mathrm{zu}$ der Forderung nach dem ius divinum die Residenzpflicht - lediglich - als „göttliche Weisung“ begriff, in COD, S. 744: Cum praecepto divino mandatum sit omnibus, quibus animarum cura commissa est, oves suas agnoscere, pro his sacrificium offerre, verbique divini praedicatione, sacramentorum administratione ac bonorum omnium operum exemplo pascere, pauperum aliarumque miserabilium personarum curam paternam gerere et in cetera munia pastoralia incumbere [...] qui gregi suo non invigilant neque assistunt, sed mercenariorum more deserunt. Zu den konziliaren Abläufen zwischen dem 8. Juni und dem 15. Juli 1563 vgl. die Tagebucheinträge Paleottis in CT, III/1, S. 654-692. Jüngst dann O’Malley 2013, S. 217-219; Fragnito 2010, S. 53-78; Wiesner 2016, S. 221-254; Becker 2016, S. 275-300. Ob die rhetorica ecclesiastica tatsächlich die konziliare Uhr des Reformdekrets um die bischöfliche Residenzpflicht zu Gunsten der Kurie zurückdrehte, bleibt noch zu untersuchen. 
welcher die Busse in eine Theologie der satisfactio („Genugtuung“) eingebettet wird. Den Gläubigen, die sich eine Vergabe ihrer begangenen Sünden erhoffen, wird demzufolge eine entsprechende compensatio angeboten. ${ }^{602}$ Mit Hilfe von Agostino Valiers De rhetorica ecclesiastica gelang es der römischen Kurie, auf die protestantische Überzeugung, dass Gott allein Sünden stets totam poenam et culpam vergebe, gezielt zu antworten. Die daraus entstandene alternative Theologie der Genugtuung verstand die Sakramentsverwaltung der Busse als eine ökonomische Wechselwirkung zwischen Sünden und göttlicher Gnade. Die Besonderheit an diesem theologischen Entwurf war, dass die Kurie dadurch den rituellen Vollzug des Busssakraments im Zeremoniell verteidigen konnte. Die Verwaltungspraxis der Sakramente wurde folglich von ihrer liturgischen Zeitlosigkeit getrennt und in das zeitliche Heilsgeschehen Christi, das sich zwischen der Fleischwerdung Gottes und dem Mess- und Kreuzesopfer ereignet, neu eingegliedert.

Diese katechetische Auslegung des Sakramentes der Busse, die Valier und Adorno im Zuge ihrer Auseinandersetzungen mit der rhetorica ecclesiastica erreichten, erlaubte es, die Verwaltungspraxis neu zu regeln. Die Kurie nutzte dann diese Neujustierung zu ihren Gunsten für die Organisation des bevorstehenden Jubeljahres, indem sie das Sakrament der poenitentia mit den urbanen Bedingungen des städtischen Raumes in Übereinstimmung brachte. Das Neuverständnis der artes praedicandi in Bezug auf die Verwaltungspraxis der poenitentia wurde vor allem vom Jesuitenorden zur Ausgestaltung seiner Priesterseminaree genutzt. Mit der päpstlichen Wahl des Jesuiten und späteren Kardinals Francisco de Toledo zum

\footnotetext{
602 Valier, De rhetorica ecclesiastica, II.13, S. 98: [...] cuius naturam David ita descripsit: 'Iniquitates meae supergressae sunt caput meum et sicut onus grave gravatae sunt super me' (Ps 37,5), ostendat ecclesiasticus orator hoc onere animam nostram per poenitentiam liberari, ita ut usque ad caelum facile possit evolare, ideo Christum Dominum ostendisse per eam regnum caelorum ad homines appropinquare cum dixit: 'Poenitentiam agite, appropinquabit enim regnum caelorum' (Mt 3,2; Mt 4,17), et beatum Ioannem Baptistam exclamasse: 'Facite fructus dignos poenitentiae' ( $L k 3,8)$, quoniam ecce adest regnum dei [...]. Vgl. dann CR, II, 5, 64: Verum haec ad paenitentiam, ut sacramentum est, minime pertinet; sed illa tantum sacramenti pars censenda est quam diximus ex praecepto sacerdotis Deo pro peccatis dependi, hoc adiuncto ut statutum cum animo et deliberatum habeamus peccata in posterum omni studio vitare. [...] satisfacere est Deo depitum honorem impendere; quod autem nemo debitum honorem Deo possit tribuere, nisi qui peccata omnino vitare constituat, satus apparet; et: satisfacere est causas peccatorum excidere, et eorum suggestioni aditum non indulgere. In quam sententiam alii senserunt satisfactionem esse purgationem qua eluitur quidquid sordium propter peccati maculam in anima resedit, atque a poenis tempore definitis quibus tenebamur, absolvimur. Bereits der 30. Kanon des Tridentiner Rechtfertigungsdekrets hatte in dieser Theologie der Genugtuung die Busse (poena) stets als poena temporalis gefasst. Vgl. hierzu COD, S. 681: Si quis post acceptam iustificationis gratiam cuilibet peccatori poenitenti ita culpam remitti et reatum aeternae poene deleri dixerit, ut nullus remaneat reatus poene temporalis, exsolvendae vel in hoc saeculo vel in futuro in purgatorio, antequam ad regna coelorum aditus patere possit: a.s. In diesem Zusammenhang dann die Debatten um die protestantische Auffassung der Genugtuung in CT, VII, S. 237-238, die in den canones 8 und 9 zur 14. Sitzung vom 25. November 1551 Eingang fanden.
} 
Prediger coram papam, der zwischen 1569 und 1571 diese Predigten im Beisitz des Ghislieri-Papstes und später vor Gregor XIII. hielt, waren es vorwiegend Mitglieder des Jesuitenordens, die eine Neuauslegung der sakramentalen Verwaltungspraxis, wie sie die Kurie forderte, erstmals vorstellten. Noch vor der Papstwahl Ugo Boncompagnis verfasste der Jesuitengeneral Francisco Borja seine Ecclesiastes sive de ratione concionandi instructio, in denen er den Priestern des Jesuitenordens empfahl, sich in ihren Predigten mehr auf die Vermittlung und Huldigung der römischen Glaubenswahrheit zu konzentrieren als häretische Meinungen zu äussern. Borjas Betonung der pastoralen Glaubenswahrheit fügte die Theologie der Genugtuung als einen essentiellen Bestandteil in das katechetische Verständnis des Busssakraments ein. ${ }^{603}$ Der Spanische Jesuit Francisco de Toledo, der zwischen 1559 und 1569 thomistische Theologie am Collegio Romano lehrte und sehr wahrscheinlich erst nach der Papstwahl von 1572 auch als magister theologiae innerhalb der Penitenzieria Apostolica tätig war, erhielt im Pontifikat Gregors XIII. ab 1573 bis 1594 wieder die Erlaubnis, coram papam zu predigen. Sowohl der englische Pilger Gregory Martin als auch der amtierende Zeremonienmeister im Boncompagni-Pontifikat Francesco Mucanzio hielten Toledos Ansehen innerhalb der Kurie in ihren Tagebüchern fest. ${ }^{604}$ In seiner im Jahr 1574 gehaltenen Predigt, die Francisco de To-

603 Borja, Ecclesiastes, S. 19: Haereses, et errores, qui cum Catholica pugnant veritate, ne temere et sine delectu tractet in suggestu Concionator, propterea quod eorum rudes, et imperiti nihil his proficiant: et quamvis doceri possint, praestat tamen ea non attingere. Scimus enim maiorem esse daemonis astutiam, quam humanam prudentiam, et vigilantiam. Prudentis itaque Ecclesiastae officium erit, robur addere argumentis Catholicae fidei, et cum ea pugnans mendacium refellere, alia via; verbi gratia, cum se occasio afferet, confirmabit obedientiam Romanae Ecclesiae debitam, firmabitque Scripturae locis, et rationibus virginitatis donum, coelibatum Sacerdotum: enumerabit fructus Religionum, Religiosorumque hominum; exaggerabit meritum bonorum operum, et poenitentiae; hortabitur ad obedientiam Principium, et Antistitum Ecclesiasticorum: item de fructu Indulgentiarum, tam pro vivis quam vita functis, et intercessionis utilitatem, et invocationem Sanctorum commendabit, ut et cultum Reliquiarum, et memorias illis consecratas. Et haex quidem omnia prudens Ecclesiastes sancto zelo ita temperabit, ut qui noverit contrarios esse errores, intelligat qua ratione refelli possint: qui vero non noverit, in sua permaneat simplicitate, et se ipse consoletur, habeatque ad monum, si forte intus exteriusque tentaretur in fide, quo se tueatur. Das Werk kann, nach Einschätzungen von McGinness 1995, S. 38, auf die 1550er Jahre datiert werden, wobei dessen Drucklegung bis 1593 warten musste. In Bezug auf die Instrumentalisierung der rhetorica ecclesiastica innerhalb des Jesuitenordens vgl. die Untersuchungen zu Soares' erfolgreicher Drucklegung seiner De arte rhetorica im Jahr 1562 in Flynn 1956, S. 367-374; idem 1957, S. 257-265.

604 Martin, Roma Sancta, S. 163-164: ,[...] it pleaseth the Pope to reteine continually Father Toledo for his preacher, bycause of his learning and judgment and credite with him self and the Cardinals and Court and citie.“ Zu Mucanzios Wertschätzung von Toledos Predigten vgl. den Tagebucheintrag in BAV, Barb. lat. 2803, f. 197v-198r: Die Domnica sequenti incipit de more sermonis prebere in Aula Consistorii Venerabilis Pr. Franciscus Toletanus, ut consuevit annis preteritis, vir eminentissimus scientiae, et in sacris litteris nostrae aetate singularis omnibus gradus [...]. Dass ihn der Zeremonienmeister als vir eminentissimus scientiae und nicht etwa als vir eminentissimus theologiae bezeichnete, wo doch Toledo 
ledo in der Aula Concistorii vortrug, erklärte er folgendermassen die Bedeutung des bevorstehenden Jubeljahres:

Quanto al primo che cosa è Giubileo. Giubileo contiene due parti: l'indulgenza plenaria cum relatione vinculorum fori conscentia. Queste due cose contiene questo nome Giubileo, la prima che è indulgentia plenaria, la seconda ch'oltre d'esser indulgentia plenaria dà la relaxatione et remissione delli vinculi del foro di conscientia. In questo ce controversia con gli heretici, ma non perché parlamo con catholici, le diremo in modo che se un catholico, se ben sa, che sono veritade possa intendere come sono et per dichiarare che cosa sia questo Giubileo diremo quattro veritade della Santa Chiesa, quattro fondamenti veri dalli quali se potrà vedere chiaramente che cosa sia quest'indulgenza et Giubileo. ${ }^{605}$

Francisco de Toledo setzte das anno santo gleich mit dem vollständigen Sündenerlass, für dessen Verwaltung das forum conscientiae verantwortlich war. Theologisch gesehen repräsentierte dieses Gewissensforum eine Trennung zwischen „Katholiken“ (catholici) und Häretikern. Mit der sakramentalen Verwaltung der indulgentiae liess sich demgemäss die römische Glaubensgemeinde von den Häretikern, allen voran den Protestanten, deutlicher trennen. Für den Jesuitentheologen Toledo stellt der Ablass - kontroverstheologisch betrachtet - die eigentliche veritas dar. Diese veritas entspricht der weiteren kontroverstheologischen Auffassung, die bereits anhand der Entwicklung der kurialen Widerlegungsarbeiten gegen die Magdeburger Zenturiatoren erläutert wurde. Die Kirchengeschichtsschreibung wurde von nun an mit dieser essentiellen kontroverstheologischen Glaubenswahrheit ausgestattet, um dadurch die Entwicklung der Romana Ecclesia seit ihren apostolischen Ursprüngen dogmatisch möglichst einwandfrei rekonstruieren zu können. Indem die Kurie im Zuge ihrer Vorbereitungen zum bevorstehenden Jubeljahr die kontroverstheologische veritas auf das forum conscientiae ausweitete, verstand sie den römischen Stadtraum als einen Ort, über den sich der göttliche Gnadenerlass für eine bestimmte Zeit ausgoss. Die Liturgie der Sakramentsverwaltung wurde somit buchstäblich verzeitlicht, wodurch jedes Sakrament auch temporaliter verstanden werden konnte. Francisco de Toledo stützt diesen zentralen Prozess in seiner Predigt zum Ju-

hauptsächlich für die Rehabilitation thomistischer Theologie innerhalb seines Ordens verantwortlich war, scheint m. E. den Jesuiten nicht in Hinblick auf dessen theologische Gewandtheit zu loben. Im Übrigen bleibt innerhalb der Forschung die Vergabe des Amtes des magister theologiae der Pönitentiarie an Toledo immer noch ungeklärt. Unbestritten bleibt aber Toledos Ansehen als exemplum eloquentiae. Vgl. hierzu Borromeo, De sacris nostrorum, S. 127: Non erat ea maiestas homini, quae rectè cum pur pura coningeretur: ideoque placuisse iam minus eum credidere. Potuit facile Toletus exemplo suo demonstrare quantum intersit ad consequendam eloquentia gloriam usus rerum. Ego, cum eum audivissem, ita sum captus admiratione viri, ut crederem nihil ultra posse desiderari, quamvis Italicè loqui non satis illi foret expeditum. Vgl. darüber hinaus die Briefkorrespondenz zwischen Sirleto und Toledo in BAV, Vat. lat. 6185, f. 83r; BAV, Vat. lat. 6191, I, f. 131r-132r.

605 BAM, O 232sup., f. 258v. Weitere Predigten Toledos zum Jubeljahr finden sich in der Handschrift BAM, G 40inf., f. 471r-475r. Obwohl letztere gleichen Inhaltes sind, geben erstere eine synthetischere Erklärung der theologischen Bedeutung des anno santo. 
beljahr auf vier Pfeiler, welche die Glaubenswahrheit ausmachen würden. Die erste dieser veritade scheint womöglich der wichtigste dieser Pfeiler zu sein, da der Jesuitentheologe bei diesem die theologische Unterscheidung zwischen einer von Gott selbst vergebenen Schuld und der Sündenvergebung an sich erläutert. Francisco de Toledo deutet den göttlichen Erlass der Schuld als eine verzeitlichte Sündenvergebung gemäss Psalm 31: Beati quorum sunt iniquitates. Toledos Psalmexegese folgt dann einer Auslegung, die bereits Augustinus in seinem De peccatorum meriti sed remissione festhielt und wonach sich die endlose Sünde in eine temporale - also zeitlich festgelegte - Schuld umwandeln lässt. ${ }^{606}$ Toledos Rückgriff auf ein augustinisches Verständnis der Temporalität der Sünden hatte letztendlich zum Ziel, die sakramentale Verwaltung der Busse von derjenigen des Taufsakraments zu unterscheiden. Während das Sakrament der Taufe dazu dient, die Erbsünde zu vergeben, wird das Busssakrament dann eingesetzt, wenn eine noch übriggebliebene Schuld - die als verlängerte Erbsünde Adams verstanden wird - auf ihre Vergebung wartet. Diese noch ausstehende Schuld kann deshalb vergeben werden, da jedem Menschen dem Johannesevangelium zufolge die incarnatio verbi immanent ist (Jh 1, 12-14), weshalb auch jeder Mensch das Heilsversprechen Christi seit der Fleischwerdung Gottes in sich trägt. ${ }^{607}$

Das Jubeljahr 1575 stellt daher nicht nur einen spezifischen Moment innerhalb des christlichen Heilsversprechens dar, in dem die menschlichen Sünden nach der Taufe vergeben werden. Das anno santo wird im forum conscientiae zu einem Augenblick der Fleischwerdung Gottes selbst erklärt, in dem sich das mysterium incarnationis stets von Neuem artikuliert. Von dieser theologischen Überzeugung lassen sich für den Jesuiten Francisco de Toledo die übrigen drei veritade ableiten. Die beiden letzten Pfeiler verweisen auf die Inkarnationsmystik Gottes in seiner Fleischwerdung durch die Geburt Christi. Dieses verborgene mysterium wird nun im Zeremoniell des Jubeljahres in eine sichtbare Offenbarung der potestas papalis verwandelt:

[...] Christo due volte ci ha redento: la prima volta per se stesso quando lui medemo morì et sparse il suo sangue per noi, et questa fu la vera redenzione. La seconda volta per gli suoi membri di Christo adimpleo ea que sunt passionum Christi, patendo molto più di quel che ho di bisogno per me, ma li patisco per gl'altri, acciché possa avanzare a gl'altri che hanno di bisogno. A talché la Chiesa ha quest'avanzo, questo cumulo delli meriti delli giusti et questo è il tesoro della Chiesa [...] è che ce potestà di spartir questo thesauro, che bella cosa saria che ci fusse il thesauro et non ce fusse chiave per poter aprirlo. Nostro Signore non le fa le cose in questo modo, ha dato il thesoro alla Chiesa e gli ha dato anchora la potestà. [...] due cose possono impe-

606 BAM, O 232sup., f. 259r-260r.

607 Augustinus, De peccatorum meritis et remissione, II, cap. 243, in PL 40, Sp. 174-175: [...] tanquam dicens, Magnum quidem hoc in his factum est, ut Deo nascerentur ex Deo, qui prius nati fuerant ex carne saeculo, quamvis creati ab ipso Deo: sed longo mirabilius factum est, quod cum istis naturae fuerit nasci de carne, beneficii vero nasci ex Deo, propter hoc impertiendum beneficium, ille qui de Deo naturaliter natus est, nasci etiam misericorditer de carne dignatus est [...] Per hoc, inquit, factum est ut nati de carne caro, postea nascendo de spiritu spiritus essemus, et habitaremus in Deo: quia et Deus natus de Deo, postea de carne nascendo caro factus est, et habitavit in nobis. 


\begin{abstract}
dire che alchuno non entri nel cielo: la colpa et la pena, qualsivoglia di queste due cose che l'uomo habbia non può entrare nel cielo, ma il Vicario di Christo ha le chiavi del regno del cielo et perciò può liberare di queste due cose, ha il thesoro et ha la chiave er aprirle et ha la potestà di spartirlo del modo che vorrà. [...] Ecco dechiarata la prima parte del Giubileo, che è indulgentia plenaria. La seconda, cioè cum relaxatione vinculorum fori conscientia sia anchora la remissione de vinculi del foro di conscientia dia se licentia alli confessori che possono assolvere di tutti gli peccati et che non sia necessario andare dal Pontefice [...] così tutto questo tempo sta serrata una porta, la quale se apre la porta aurea, la Porta Santa in segno che sta aperto il thesoro della Chiesa et vengono a Roma tutti a guadagnar questo Giubileo et indulgentia plenaria, così anchora si vede che commandava Iddio, che tutti gli giudei anchora quelli che stavano fuora della terra di promissione venissere tre volte all'anno a Gerusalemme [...]. ${ }^{608}$
\end{abstract}

In Francisco de Toledos Predigt zum bevorstehenden Jubeljahr überlagerte sich die Fleischwerdung Gottes mit dem Kreuzes- und Messopfer Christi, da für Toledo Letzteres die eigentliche plenaria indulgentia bedeutete. Die artes praedicandi hatten damit in der rhetorica ecclesiastica die päpstliche Amtsmacht als locus poenitentiae bestätigt. In den Vorbereitungen zum giubileo während des Boncompagni-Pontifikats Gregors XIII. ist somit festzustellen, dass die bischöflich geprägte rhetorica ecclesiastica endgültig in Einklang mit den kurialen Vorstellungen zum Sündenerlass und der dafür notwendigen Sakramentsverwaltung gebracht wurde. Gleichzeitig liess sich damit die zeremonielle Liturgie des Jubeljahres als feierlicher Moment des göttlichen Gnadenerweises verstehen. Am Festtag der Geburt Christi fand demzufolge in den kurienzeremoniellen Vorschriften eine Übertragung der himmlischen und somit zeitlosen Gnade auf die zeitlich begriffene Menschheitsgeschichte statt. Cesare Baronio hielt selber im ersten Band seiner Annales Ecclesiastici fest, dass im Augenblick der Fleischwerdung die Ankunft des logos den Anfang einer jeden Kirchengeschichtsschreibung darstelle. ${ }^{609}$ Diese Einsicht des Oratorianers und späteren Kardinals verlangt nach einer Antwort auf die grundlegende Frage, wie im Kurienzeremoniell zum Jubeljahr 1575 ein spezifisches Verständnis einer theologisch bereits in groben Zügen entworfenen Kirchenhistorik auftreten konnte.

\title{
5.2 Unschärfen römischer Liturgie im rituellen Vollzug des Jubeljahres 1575
}

Francisco de Toledo verwies mit seiner Predigt, in welcher er die Bedeutung des Jubeljahres erläuterte, auf eine spezifische Form der mittelalterlichen Schatztheologie. Zuerst muss an dieser Stelle eine Rekonstruktion der Vorbereitungen zum

608 BAM, O 232sup., f. 263r-264r, 266r.

609 Die Kirchenhistoriographik sollte sich daher als eine Operation der Verzeitlichung einer zeitlosen Sphäre der göttlichen Gnade im Heilsversprechen Christi und seiner Erfüllung im Kreuzessowie Messopfer verstehen: Ann. Ecc., I, S. 7-9. 
giubileo anhand Francesco Mucanzios Zeremonialtagebuch vorgenommen werden, um danach diese Rückbesinnung auf die Schatztheologie einordnen zu können. Es sollte sich nämlich zeigen, dass die zeremoniellen Vorbereitungen und deren effektive Durchführung im Rom Gregors XIII. in liturgischer Hinsicht noch keine eindeutige Trennung zwischen römischem und diözesanem Ritus bewerkstelligen konnten. Gleichzeitig war aber eine solche Unschärfe, wie im Folgenden gezeigt wird, eine der zentralen Voraussetzungen dafür, das Jubeljahr - wie es die Zeitzeugen festhalten würden - als „l'Anno più santo“ inszenieren zu können. ${ }^{610}$ Bevor auf diese wichtige Unschärfe eingegangen werden kann, soll zuerst Cesare Baronios Rolle innerhalb Filippo Neris Priesterbündnis beleuchtet werden.

Vor ihrer päpstlichen Anerkennung als Priesterkongregation hatten die Oratorianer immer noch nach einer kirchenrechtlich anerkannten Form der pastoralen Seelsorge, die Filippo Neris Priesterversammlungen deutlich von den römischen Bruderschaften unterscheiden sollte, gesucht. Carlo Borromeo schlug diesbezüglich vor, dass Neri und seine Versammlungen in San Giovanni dei Fiorentini nach Mailand überführt werden sollten. ${ }^{611}$ Vor dem Hintergrund der Bedeutung, welche der rhetorica ecclesiastica für die rituelle Bestimmung des Predigtwesens zukam, soll geklärt werden, wie Baronio in seinen eigenen Predigten die artes praedicandi verstand. Zusätzlich zu den Heiligenlektionen, die Baronio nach seiner Priesterweihe in San Giovanni dei Fiorentini 1564 zu predigen begann, wurde ihm ab 1568 die Verantwortung für das officium der Fastenzeit anvertraut. Über diese neue Verantwortung äusserte sich Baronio in einem Briefschreiben vom 4. Februar 1568 folgendermassen:

Io per gratia di Dio, sto bene, se ben stanco. Questi mi minacciano che vogliono ch'io solo predichi tutta questa quadragesima intera: essendo che nella Chiesa nostra si è aviata bona

610 Zaccaria, Trattato, I, S. 80: „[...] qual Giubileo Roma non avea sino allora veduto l'uguale [...].“ Vgl. hierzu dann Pastor 1893-1933, Bd. 9, S. 143-145; Bargellini 1974, S. 81; Jacks 1989, S. 137; Wisch 1990, S. 82-117; Freiberg 1991, S. 66-87.

611 Vgl. supra, Kap. 1.2. Wie aus einem Briefschreiben Baronios an seinen Vater vom 25. Februar 1568 entnommen werden kann, besass er selber Kenntnisse dieser Wünsche Borromeos, das Oratorium nach Mailand zu überführen. Vgl. das Briefschreiben in BVR, Q 46, f. 45v-46r: „Ho havuto la vostra, e visto quanto scrivete. Non poco dispiacere con mia Madre: che io voglia andare a Milano. Io non sò come questa tal persona, qual non sò chi sia, habbia detto tal cosa assertivamente; non sapendo bene quel ch'è passato. La cosa è stata in questo modo. Che Mess. Costanzo Mastro di Casa del Rmo Borromeo haveva parlato a Mess. Filippo, che si fusse contentato di me, che mi haverebbe seco menato in Milano, che il detto Rmo Borromeo si sarria di me servito. E Mess. Filippo senza altro lo escluse, che no. E cosi sta la cosa tutta esclusa. Non ci è garbo, ne modo ch'io mi possi partir da Roma pur una giornata di lontano, che questi fiorentini n'hanno gelosia, e sempre temeno. La conclusione è ch'io ho trovato il riposo in questo a l'anima: se bene il corpo in sempre travagli. Si che state pur sicuri, e con la mente in pace; ne vi fate movere d'ogni vento. Io per gratia del Signore stò bene. Dubito che bisognara predicare la quadragesima, almanco le feste: tanto che son messo in ballo e durera questa danza, fin che mi durera il fiato; benedetto sia Dio. Iesu d'ogni male vi guardi.“ 
audientia. Io recalcitro quanto piu posso: perchè non mi pare esser di tal nervo, sendo gia infiacchito per l'altre occupationi. ${ }^{612}$

Baronio muss mit „anderen Beschäftigungen“ seine eigenen Heiligenlektionen gemeint haben, die er in ihrer patristischen Überlieferung homiletisch ableitete. Die quadragesima, das liturgische officium der Fastenzeit, stellte für den Oratorianer Baronio deshalb eine Herausforderung dar, weil sich in deren rituellem Vollzug zwei liturgische Dimensionen verschränkten, die er bis zu diesem Zeitpunkt noch nicht beherrschte. Indem die Fastenzeit als österliche Busszeit verstanden wurde, musste gleichzeitig in ihrem officium das mysterium des Kreuzes- und Messopfers Christi in der sakramentalen Verwaltung der Busse hervorgehoben werden. Deshalb stellte die Fastenzeit auch einen deutlichen Gegensatz zum jährlich stattfindenden Karneval dar. Insbesondere Carlo Borromeo hatte diesen fundamentalen Gegensatz zwischen Busszeit und Karneval während seiner Verwaltung der Mailänder Diözese stark betont. ${ }^{613}$ Es ist nicht auszuschliessen, dass Baronios Verständnis der quadragesima, wie er es im ersten Band seiner Annales Ecclesiastici zum Ausdruck brachte, von seinen Predigten in San Giovanni dei Fiorentini beeinflusst wurde. Die Homiletik der Fastenpredigten war aber im Mailand Borromeos einem ambrosianischen Ritus verpflichtet. Cesare Baronios Auseinandersetzung mit der quadragesima zeigen hingegen, dass er die Fastenzeit in einem gregorianisch-augustinischem Verständnis verstehen wollte. Dieses spezifische Verständnis der Fastenzeit stimmte mit den im Breviarium Romanum enthaltenen lectiones zur österlichen Busszeit überein. Allerdings war es der Kurie erst nach dem Jubeljahr 1575 möglich, diese gregorianisch-augustinische Auslegung der Busse und der quadragesima auch im Kurienzeremoniell festzulegen. Baronio zeigte im ersten Band seiner Annales die ursprüngliche Vielfältigkeit eines ritus qudragesimalis nach römischem Verständnis auf, dem auch der ambrosianische Ritus angehörte. Baronio zufolge setzte ab den Homilien Gregors d. Gr. ein dynamischer Prozess der rituellen Vereinheitlichung innerhalb der Ecclesia Romana ein. Mit der oratione wurden dann die verschiedenen rituellen Ausprägungen der quadragesima im Kirchenkörper ekklesiologisch zusam-

612 BVR, Q 46, f. 46r; Baronius, De origine Oratorii, S. 113: Contigit post multos annos, Florentinos Romae degentes boni aemulos adiisse ipsum Patrem atque ipsum rogasse ut ipsorum, quam Romae habebant ecclesiam gubernandam, susciperet idque pluribus egere donec fierent voti compotes. Transmisit illuc Pater quos vetustiores habebat delectos filios [...].

613 Carlo Borromeos Predigten anlässlich einzelner Sonntagsfeiern für die quadragesima zwischen 1569 und 1571 befinden sich in BAM, F 193inf., f. 37v-38r, 48v, 55r, 68v. Vgl. Muir 2005, S. 93-124; Bossy 1985, S. 42-45, 50-51; Myers 1996, S. 38-47; Burke 1996, S. 207-209; De Boer 2000, S. 76, 174-176, 248. Vgl. in diesem Zusammenhang auch das folgende Briefschreiben Baronios vom 11. April 1569 an seinen Vater, in dem Busse und Karneval als Gegensätze verstanden werden, in BVR, Q 56, f. 14v: „Con questa vi dò aviso del mio ben stare, e solo mi fa male le troppo comodità e delitie e pensando io di venire alla via di Dio per far la penitenzia parmi esser venuto a far Carnevale.“ 
mengeführt. ${ }^{614}$ Baronios Auslegungen des rituellen Wandels der quadragesima zeigten, dass der Ritus der Fastenzeit zuerst innerhalb eines ekklesiologischen Rahmens gefasst werden musste. Diesem Rahmen war zugleich die Bedingung eingeschrieben, dass sich der rituelle Wandel der Fastenzeitliturgie in der Entwicklung der Ecclesia Romana stets auf seine apostolischen Ursprünge zurückführen liess. Deshalb stellte für Baronio die Liturgie der quadragesima in ihrem rituellen Verständnis den eigentlichen Beweis einer Kontinuität der Kirche seit ihren apostolischen Ursprüngen dar. Die einzelnen lectiones im Breviarium Romanum zur quadragesima zeigen daher noch nicht, wie das Sakrament der Busse gemäss der traditio Apostolica an sich verwaltet werden musste. In diesen Lektionen werden die Festtage im liturgischen Kirchenkalender nur den einzelnen patristischen Homilien und Bibelstellen angepasst.

Somit musste zuerst die Sakramentsverwaltung, allen voran diejenige der Busse, von ihrer starken Anlehnung an ein ambrosianisches Verständnis der Sakramente entkoppelt werden. Erst dadurch liess sich ein originär römischer Ritus Ecclesiae formulieren. Dieser römische Ritus der sakramentalen Verwaltungspraxis war eng mit der zeremoniellen Vollstreckung der Sakramentsverwaltung verbunden. Mit diesem Ritus wurde die Predigtliturgie mit den in den liturgischen Büchern enthaltenen Bestimmungen dazu in Einklang gebracht. Dass die Kurie selbst die Notwendigkeit eines römischen Rituale noch vor dem Jubeljahr erkannte, lässt sich im Schreiben Gabriele Paleottis an Guglielmo Sirleto vom 23. Januar 1574 erkennen:

614 Ann. Ecc., I, a. 57, S. 489-490: At vero non una erat eademq. omnium Quadragesimalis observatio, ut omnes totidem, aeque dies transfigerent ieiunantes: remissir enim quorumdam eius temporis erat ieuniorum prefunctio, quos tamen tolerabat Ecclesia [...] Diversas alias fuisse diversarum ecclesiarum consuetudines [...] in Occidente observare consuevit olim Ecclesia Mediolanensis, ut testatur Amrosius, sic dicens: Considera: Quadragesima totis praeter Sabbatum \& Dominicam ieiunantur diebus: hoc ieunioum Domini Pascha concludit. [...] Rursus etiam in Ecclesia Mediolanensi illud Ambrosius observandam admonuit, ut integri dies quadragintaduo a fidelibus ieunio transfigerentur, ea nimirum ex causa, qud sicut Israel a captivitatis Aegypticae iugo liberatus totidem stationibus seu mansionibus ad terram promissionis pervenit; eodem fere modo, eodemq. numero ieiuniorum, quae (inquit idem Ambrosius) mansiones quaedam nostrae sunt [...] In Ecclesia Romana eadem ratio habebatur, dum quadragintaduos dies Quadragesima contineret, sed ex eis triginta sex tantum diebus fidelis ieiunabant, alia tamen ratione, quam S. Gregorius pro concione ad populum his verbis declarat [...] His de Quadragesimae ieunio qua potuimus brevitate contractis, iam de cereris, que ex traditione itidem Apostolica in Ecclesia sunt antiquitus observata ieunia, instituamus orationem. Vgl. entsprechend die Anordnungen der einzelnen Lektionen in Brev. Rom., S. 305-353. Dass Baronios Predigten für die quadragesima zwischen 1569 und 1571 dem Breviarium Romanum folgen mussten, kann aus der Tatsache abgeleitet werden, dass ab 1567 die päpstliche Opposition gegen das Oratorium, wie bereits während des Carafa-Pontifikates beobachtet wurde, von Neuem aufflammte. Vgl. hierzu die beiden Zeugenaussagen in Primo Processo, I, S. 383; ibid., III, S. 144. Es sei an dieser Stelle angemerkt, dass eine umfassendere Untersuchung zu den quaresimali, die nach dem Breviarium und Missale Romanum entstanden, den Rahmen dieser Untersuchung deutlich sprengen würden. Solche Predigtsammlungen finden sich aber hauptsächlich im Umfeld der Jesuiten Francisco de Toledo und Alfonso Salmerón, in APUG, F.C. 1608rec, f. 2r-316v, 319r-452v. 


\begin{abstract}
Habbiamo nella nostra casa de Cathecumini una Neophita, che desideraria monacarsi, et pare che queste nostre suore di quà, per esser ella stata hebrea non si contentino molto di pigliarle. Intendo che costi è il Monast(eri)o dove si ricapitano tal Neophite, se paresse à V.S. Ill.ma di far dar luoco in esso [...] faria cosa molto grata à tutta la nostra Congregatione. Hebbi la sua con il luoco del Nanzianz(en)o diche la rengratio, et mi serà charo, ch'ella m'avisi, che cosa intendano li lereti per la parola, Dipticha, essendo che alcuni dicano, che s'intende per illa none et Memento della Missa, et ancor di nuovo gli racordo il Rituale, per essercine gran bisogno. ${ }^{615}$
\end{abstract}

Im Zusammenhang mit der rituellen Formulierung der Sakramentsverwaltung durch die Kurie ist dieser Brief Paleottis deshalb von Bedeutung, weil der Kardinal und Bischof von Bologna hier den Gebrauch eines solchen Rituale speziell für den Vollzug der Messefeier anspricht. Die bischöfliche Verwaltung einzelner Diözesen umfasste an erster Stelle die sonntägliche Messzelebration. Paleotti zufolge sollte dieses neue Rituale daher primär für die 1568 in seiner Diözese von Bologna gegründete Casa dei Catecumeni verwendet werden. In Rom wurde 1577 ebenfalls ein Collegio dei Neofiti gegründet, zu deren Kardinalprotektoren Filippo Guastavillani, Guglielmo Sirleto und Giulio Antonio Santori ernannt wurden. ${ }^{616}$ Im Konsistorium vom 26. April 1575 wurde der Kardinal Santori dann mit den Revisionen des Rituale Romanum beauftragt. Er sollte eine überarbeitete Fassung des Rituale vorbereiten, wofür er zwei Jahre später dem Santo Uffizio einen Plan seiner Revisionsarbeiten vorlegte. Der Bischof von Brescia, Domenico Bollani, schenkte Santori aus diesem Grund sein 1575 in Brescia gedrucktes Rituale sacramentorum, das der Bischof anhand der Tridentiner Dekrete zu den Sakramenten zusammengestellt hatte. ${ }^{617}$ Eine in der Biblioteca Vallicelliana aufbewahrte Handschrift, die ein ottonisches Pontificale aus dem 11. Jahrhundert überliefert, befand sich im Besitz des Portugiesen Achille Stazio. Stazios Privatbibliothek wurde nach seinem Tod 1581 der Kongregation des Oratoriums vererbt, weshalb dieses Pontificale zu den ersten Handschriftensammlungen der Valli-

615 BAV, Vat. lat. 6192, I, f. 9r. Bislang blieben Untersuchungen zu einem solchen Rituale, das noch vor der offiziellen und unter Paul V. 1614 herausgegebenen editio princeps entstand, im Zusammenhang mit dem römischen Kurienzeremoniell aus. Vgl. zuletzt Löwenberg 1937, S. 14-15; Popelyastyy 2018, S. 196-197.

616 Bull. dipl. rom., VIII, S. 188-191, 199: Ut vero ipsius collegii conservationi bonoque regimini, tam in his quae ad institutionem et disciplinam, quam quae ad victum, vestitum aliaque huiusmodi necessaria pertinent, opportunius consulatur, dilcetos filios nostros Gulielmum Sirletum Sancti Laurentii in Panisperna, et Iulium Antonium S. Bartholomaei in Insula S. Severinae titulorum presbyteros, necnon dilectum filium Philippum Vastavallium S. Mariae Novae diaconum, S. R. E. cardinales, eiusdem collegii protectores constituimus ac deputamus, quorum consilio et ope supradicta et alia quaecumque ad eosdem in collegio admittendos scholares retinendosve ac dimittendos spectantia agantur, statuantur et ordinentur [...]. Vgl. auch Possevino, Bibliotheca selecta, S. 440. Das Collegio dei Neofiti kann als Ausbau der durch Paul III. Farnese 1545 eingerichteten Casa dei Catecumeni betrachtet werden: Lazar 2005, S. 99-124.

617 BAV, Stamp.Barb.B.VII, c. 15r. Zum Konsistorium vom 26. April 1575 vgl. das Dokument in ASV, Misc. Arm. LII, 17, f. 248r, das über die revisione del Rituale spricht. 
celliana gezählt werden kann. Santori musste dieses ottonische Pontificale selber gekannt haben, denn aus seinem eigenen Nachlass wird deutlich, dass er sich für das neue Rituale auf einen ordo missalis berief, der in den älteren Pontifikalien überliefert war. ${ }^{618}$ Dieses Bedürfnis der Kurie, selber ein nach eigenen Massstäben gültiges Rituale sacramentorum vorzulegen, zeigt deutlich, dass dieses Rituale für alle Bischofsdiözesen allgemeinverbindlichen Charakter in Bezug auf die Sakramentsverwaltung haben sollte.

Die Entstehung von Cesare Baronios Annales Ecclesiastici lässt sich deshalb mit der liturgisch-zeremoniellen Ausgestaltung der sakramentalen Verwaltungspraxis vereinbaren, da Baronio mit Hilfe dieser die entscheidende Frage, wie solche officia rituell zu gestalten und entsprechend auszuführen sein sollten, nachgehen und beantworten konnte. Dieser Diskurs um die sakramentale Verwaltungspraxis fand auch Eingang in die kurialen Widerlegungsarbeiten gegen die Magdeburger Zenturiatoren ab dem Boncompagni-Pontifikat Gregors XIII. Die Congregatio Germanica strebte selber danach, die bischöfliche Sakramentsverwaltung einzelner Diözesen im Reich dem römischen Ritus anzugleichen. Ziel der Kongregation war es somit, die Diözesanverwaltung mit der kontroverstheologischen Überzeugung, dass im Ritus der sakramentalen Verwaltung das zeitlose Heilsgeschehen verzeitlicht werde, zu vereinbaren. Das für das anno santo ausgestaltete Kurienzeremoniell bot dafür eine geeignete Grundlage, weil es das in den einzelnen Sakramenten enthaltene, zeitlose Heilsversprechen Christi in seinem rituellen Vollzug verzeitlichte. Dieses Kurienzeremoniell liess sich daher für eine den kurialen Massstäben genügende historia ecclesiastica ausgiebig verwenden. Die Kurie kam während ihrer Vorbereitungen zum anno santo zu einem spezifisch römischen Verständnis darüber, wie die einzelnen Sakramente bei der Messzelebration rituell zu verwalten waren,, und zwar zum Zeitpunkt, als sie damit begann, das Zeremoniell der Öffnung der Porta Santa neu zu gestalten. Der Theologe und Servit Cirillo Franchi erklärte in seinem dem Boncompagni-Papst gewidmeten und 1575 gedruckten Kommentar zum Jubeljahr die Bedeutung dieses zeremoniellen Ereignisses. Indem der Papst selbst die „Heiligen Pforten“ der Petersbasilika während der Weihnachtsvigil öffnet, wird dieser Moment offiziell als eigentlicher Auftakt zu jedem Jubeljahr angesehen. In der Auslegung des Serviten Franchis fällt daher der vollständige Sündenerlass mit dem Beginn des Jubeljahres, das als verzeitlichtes Heilsgeschehen Christi ab der Fleischwerdung Gottes verstanden wird, zusammen: Die rituelle Öffnung der Porta Domini, die zur Porta Paradisi vorgeführt wird, knüpft an den Zeitpunkt der Wiederauferstehung (resurrectio Domini) an. Die Geburt Christi (nativitate Domini) fällt dadurch mit dem Heilsversprechen der Wiederauferste-

618 Zu Santoris Nachlass vgl. BAV, Barb. lat. 549, 559, 560, 562, 563, 631, 632, 697, 699, 681. Vgl. hierzu insbes. Tamburini 1998, S. 119-120. Das Pontificale aus dem Besitz Stazios befindet sich in BVR, D 5, f. 1r-150v. Zur Rolle Stazios als Bibliothekar vgl. dann Pastor 1893-1933, Bd. 7, S. 313; idem, Bd. 9, S. 797; Rosa Corsini 1987, S. 14-16; Formica 1989, S. 9-10. 
hung zusammen. ${ }^{619}$ Der Zeremonienmeister Francesco Mucanzio hielt in seinem Tagebuch zusätzlich fest, dass dieses Zeremoniell der feierlichen Öffnung der Porta Santa auf das Jubeljahr Julius' III. zurückgehe. Da aber dieses Zeremoniell sowohl 1550 als auch 1525 vom rotulo antiquo abwich, wurde mit diesen beiden Öffnungen der Porta Santa eine Zeit der infortunia und der direptio eingeläutet. Deshalb setzte Papst Gregor XIII. eine eigenständige Kardinalskongregation ein, die sich der Neuerung dieses spezifischen Zeremoniells annahm und die Mucanzio zufolge auch angenommen wurde (risolutum). ${ }^{620}$ Bei dieser Kardinalskommission muss es sich um die vom Boncompagni-Papst 1572 einberufene Zeremonialkongregation

619 Franchi, De anno iubilei commentarius, S. 68-69: A quo sancto instituto Ecclesiae consuetudinem istam in Ibuleo plenario sanctissimam recepit portas aperiendi, quo à poenis innunctis à sacris canonibus fideles declaret absolutos esse, indulgentiarum virtute. Haec igitur de causa Summus Pontifex in Vigilia Nativitatis Domini Nostri Iesu Christi omnium Romae tunc temporis degentium concursu tubis clangentibus, clericis omnibus psallentibus, pijs orantibus, Portam sanctam D. Petro consecratam tot sacris ceremonijs aperit. Quo remissionem, \& absolutionem poenarum pro peccatis sanctis fidelibus omnibus exanctè poenitentibus donari agnoscatur per munus Apostolicum illi Christo Domino nostro commissum. [...] Sed porta hac portam Domini verius ostendit, per quam iusti intrabunt. Dua enim sunt portae, inquit D. Hierony. in serm. de Resurrectione Domini. Porta Paradisi, \& porta ecclesia, per portam ecclesiae intramus portam Paradisi.

620 BAV, Chig.L.II.30, f. 266v. Aus einer späteren memoria des Zeremonienmeisters Urban VIII., Michele Lonigo, kann erschlossen werden, dass das Zeremoniell der Öffnung der Porta Santa auf Alexander VI. und damit auf das Jubeljahr 1500 zurückgeht. Vgl. hierzu die memoria aus BAV, Barb. lat. 2974, zit. n. Visceglia 2002, S. 241: „L'uso d'aprir et serrar nel principio et fine dell'anno del Giubileo quelle porte delle quattro principali Basiliche di Roma che si sogliono chiamar Santa non solo non è antico, ma anzi [...] non si trova memoria, o inditio alcuno di queste porte, sistema novo et moderno, introdotto forse attorno al Pontificato di Alessandro VI [...] Poiché rappresentandosi, queste porte, le porte del Cielo, o quelle del tesoro di Santa Chiesa et il Sommo Pontefice nell'aprirla insinuandosi la potestà, che tiene da Christo di poter a sua voglia aprir, et serrar le porte del Cielo e del tesoro predetto, sendo questa potestà stata conferita da Christo in San Pietro et successori sotto metafora di chiavi, et non di martello [...] Vorrei, che per Bolla speciale di N.S. si subrogasse il loco della vecchia Porta a man destra della Porta di Bronzo, la qual ornata decetissimamente non si murasse, o smurasse più mai, ma con due grandi e bellissime Chiavi, una d'oro e l'altra d'argento a tempi debiti s'aprisse et serrasse per mano del Sommo Pontefice [...] perché s'alluderebbe mirabilmente alle due Chiavi dell'Ordine e della Giurisditione [...] s'esprimeberebbe piùs efficacemente il misterio, et si dimostrerebbe il Sommo Pontefice quello che veramente è portinai del cielo e non muratore." Vgl. auch den Eintrag vom 18. Dezember 1500 in Burchardus, Diarium, I, S. 582: [...] quem dicunt canonici basilice esse Portam auream nuncupatam que singulo centesimo jubileo anno consuevit per summos pontifces aprire, quod et sepius audivi in vulgo dici et teneri. Tatsächlich fand also unter Alexander VI. vielmehr eine zeremoniell-liturgische Festigung der Eröffnung statt, die an Stelle einer porta aurea für die Basilica Vaticana nun eine neue Tür installieren liess. Vgl. auch die Stelle in Alfarano, De Basilica Vaticana, in BAV, Arch.Cap.S.Pietro. G.5, f. 12v-13r: „Sopra la Porta Santa vi è l'Arme de PP. Julio III et è scritto Julius III Pont. Max. Portam hanc aperuit et clausit anno Jubilei MDL apertam prius ab Alexandro VI Anno MD et a Clemente VII Anno MDXXV; ma nell'anno 1576 Gregorio XIII havendol'aperta et serrata pose quest'altra iscrizione: Gregorius XIII Pont. Max. hanc Sanctam Portam a Julio III Anno MDL apertam et clausam aperuit et clausit Anno Jubilei MDLXXV. 
gehandelt haben, welche Gregor XIII. ebenfalls mit der Ausarbeitung eines Kurienzeremoniells für das bevorstehende anno santo beauftragte. Ab 1573 zählte auch der spätere major poenitentiarius Stanislaus Hosius neben dem päpstlichen Sekretär Tolommeo Galli und Gianfrancesco Gambara zu ihren Mitgliedern. Diese Einsetzung Hosius in die Zeremonialkongregation ist als Resultat der Einwirkungen Carlo Borromeos auf die Kurie zu betrachten. Denn obwohl der Mailänder Bischof selber nicht in Rom anwesend war, übte er über den Ermländer Bischof dennoch einen entscheidenden Einfluss darauf aus, wie das Kurienzeremoniell für das bevorstehende Jubeljahr sowohl theologisch als auch liturgisch zu gestalten war. Zudem war Borromeo auch mittels seines Korrespondenten Cesare Speciano über die zu treffenden Neuerungen bezüglich des römischen Messritus informiert worden. Borromeo selber scheint sich dann für das neue Missale Ambrosianum, an welchem er zusammen mit Pietro Galesini arbeitete, an die Bestimmungen dieser römischen Zeremonialkongregation stark angelehnt zu haben:

Con questo ordinario mando un libro delli secreti della messa et tutte le copie di quelle tavolette che ho saputo trovare. Mando ancora la resolutione delli dubii delle ceremonie li quali per [...] diligenza, che vi sia usata, non si sono potuti haver prima; et questo anche perché il maestro di ceremonie li ha voluti consultare nella Congreg(atio)ne delle Ceremonie, si come $\mathrm{mi}$ ha fatto più volte dire. Mando ancora costì altre resolutioni fatti sopra il vestire di Cardinali in certi giorni. Il ceremoniale non si può havere perché tuttavia si va compilando nella suddetta Congreg(atio)ne. ${ }^{621}$

1573 verabschiedete die römische Zeremonialkongregation insgesamt 43 Reformdekrete. Zusätzlich dazu finden sich zwei Bestimmungen darüber, wie der Festtag der Geburt Christi zu feiern sei: Während nämlich die Kappellensänger die Fleischwerdung des Heiligen Geistes anstimmen und die versammelten Kardinäle kniend (genuflectant) an der päpstlichen Messe teilnehmen, sollte im rituellen Vollzug des

621 Briefschreiben Specianos vom 6. März 1574 in BAM, F 129inf., f. 312r. Es muss sich hier um das vom Zeremonienmeister Burckhardt erstellte zweite Buch seines Caeremoniale gehandelt haben, auf das Mucanzio über einen Neuentwurf de Grassis zurückgriff und sich damit an die Arbeit zur Emendation eines neuen Zeremonienbuches machte. Diese sollte allerdings erst unter Paul V. durch den Zeremonienmeister Paolo Alaleona de Branca zum Abschluss gelangen. Burchards Diarium caeremonialium findet sich in BAM, D 128inf., f. 1r-424r. Der Erzpriester von Santa Maria Rotonda ad Martyres verfasste am 23. April 1573 ebenfalls ein Schreiben an Borromeo, in welchem er über die anscheinend recht heftigen Diskussionen innerhalb der Kongregation schrieb, in BAM, F 126inf., f. 399r: „Perchés era nata una gran disputa nella congregatione de le cerimoniae e perché sappi che se ne haveva da parlar ne feci un poco discorso [...] e per soddisfar a tutti l'ho fatto stampare e ne mando una copia a Vostra Signoria." Vgl. hierzu insbes. Bölling 2006, S. 41; idem 2007, S. 65-67; Zunckel 2013, S. 357. Zu der am 5. November 1572 ins Leben gerufene Zeremonialkongregation „per ridurre le cerimonie all'uso antico et levar gli abusi trascorsi si nella venuta dei principi, come de loro ambasciatori et di molt'altre cose" vgl. neben BAV, Chig.L.II.30, f. 85v auch Pastor 1893-1933, Bd. 9, S. 42, 867-877, wo auszugsweise eine auf den 20. Februar 1574 zu datierende Relatione su papa Gregorio XIII, la sua corte et il collegio dei cardinali abgedruckt ist. 
Weihnachtsfestes das Osterfest bereits verkündet werden. ${ }^{622}$ Die verabschiedeten Reformkapitel der Zeremonialkongregation zeigen, dass sich im Kurienzeremoniell zur Öffnung der Porta Santa eine Theologie der Fleischwerdung mit der Einlösung des Heilsversprechens Christi im Kreuzes- und Messopfer verband. Im Konsistorium vom 1. Dezember 1574 wurden auch die Kardinäle, welche die „Heiligen Pforten“ der übrigen römischen Patriarchalbasiliken öffnen sollten, bestimmt. Die Öffnung der Porta Santa von San Pietro wurde vom Papst selber administriert. ${ }^{623}$ Gemäss den Einträgen im Zeremonialtagebuch Francesco Mucanzios ist das Zeremoniell für die Öffnung der Porta Santa in ein officium ante aperitionem und in ein officium post aperitionem aufgeteilt. In diesem Zeremoniell ruft der Papst die übrigen Kardinäle dazu auf, die Porta Iustitiae als Porta Domini zu öffnen. Durch diese Pforten wird jedem Gläubigen der Eintritt in das Reich Gottes für eine kurze Zeit gewährt. Auf diesen feierlichen Aufruf des Papstes folgt der Psalmengesang Domino jubilate (Ps 99). Die Sängerkappelle betont mit diesem Gesang die actiones nostras quae sumus Domine adiuvando. Das rituelle Durchschreiten der geöffneten Pforten in ein nun irdisch erweitertes Himmelreich gleicht mit dem daran anschliessenden officium post apertitionem der mosaischen Befreiung des Volkes Israels aus der Sklaverei. In seinen Tagebucheinträgen unterscheidet der Zeremonienmeister Mucanzio zwei Arten der zeremoniellen Öffnung der Porta Santa, wie sie unter Clemens VII. und Julius III. durchgeführt wurde. Dabei arbeitete er insbesondere die deutlichen Unterschiede zwischen dem officium ante aperitionem während des verspäteten Jubeljahrs 1550 und demjenigen Clemens’ VII. aus. Mucanzios Einträgen zufolge

622 BAV, Chig.L.II.30, f. 159v-160r. Die Capita Reformationum Cappellae aus BAV, Vat. lat. 12344, f. $5 r-10 v$, finden sich auch abgedruckt in Staubach 2008, S. 407-411 Die Handschrift enthält ebenfalls eine zwischen 1576 und 1625 überlieferte Collectanea de apertitione et clausura Portae Sanctae anno Jubilae, in ibid., f. 92r-145r. Eine Abschrift der verabschiedeten Kapitel findet sich auch in ACP, vol. 59, f. $14 r-20 r$.

623 BAV, Chig.L.II.30, f. 265r-v: Diebus praeterritis habita fuerint plura Consistoria in quibus nihil aetum quod ad Caeremonias pertineat, eo tamen excerpto, quod in ultimo Consistorio ante quartiam Dom. Adventus S.D.N. deputavit tras legatos de habere ad aperiendum Portas Sanctas in tribus Basilics Urbis Ill.mos et R.mos Dominos Ioannem Card.lem Moronium Sacri Collegij Decanum, ad ecclesiae S. Pauli uti episcopum Hostiensem, in cuius Dioecesi ecclesia illa est sita, ac etiam uti Protectore Religionis S. Benedicti, cuius ordinis religiosi in ea commorantur. Item Marcum Sitticum Card.lem de Altaemps ad ecclesiam S. Jo. Lateranensis ubi illius Archipresbiterium, et Allexandrum Card.lem Sfortiam ad ecclesiam S. Mariae Maioris pariter uti illios Archipresbyterum. Vgl. hierzu auch den etwas ungenaueren Eintrag in Santoris Diario concistoriale, in Tacchi Venturi 1903, S. 248: Fuit concistorium secretum in quo, post audientiam, Sanctissimus D.N. dixit instare annum iubilaei et cum non possit personaliter interesse ad aperiendas portas sanctas omnium basilicarum, nisi s. Petri, delegavit cardinali Morono episcopo ostiensi reserationem portae sanctae ecclesiae s. Pauli, praesertim quia est protector Ordinis. In basilicis vero s. Ioannis Lateranensis, et s. Mariae Maioris, non bene audivi, huiusmodi portae sanctae aperitionem illarum archipresbytero, declarans quod indulgentiarum concessionem, eamdem vim habere ac si per se ipsum aperirentur. Et fuit ibi extra ordinem dictum quod Ursinus, loco cardinalis Altempis aegrotantis, aperiret portam s. Ioannis. 
wurde in diesem officium der Aufruf introibo in Dominum tuam Domine mit der Antwort adorabo ad Templum Sanctum tuum erwidert. Dadurch wurden zwei noch bis zum Del Monte-Pontifikat Julius' III. unterschiedliche Dimensionen im Zeremoniell der feierlichen Öffnung der Porta Santa miteinander verbunden. Dies führte dazu, dass das officium post aperitionem als eigentliche exultatio des Jubeljahres erschien. Erst nach der Öffnung der Heiligen Pforten sollte nämlich mit der oratio ad Dominem der zeitlich begrenzte Eintritt in das Himmelreich Gottes gewährt werden. ${ }^{624}$

Aus Francesco Mucanzios Tagebucheinträgen wird deutlich, dass die Mitglieder der Zeremonialkongregation dieses officium aus dem Pontifikat Julius' III. aufrechterhalten wollten - allen voran der Kanoniker von San Pietro, Francesco Curtio. ${ }^{625}$ Curtio verfasste diesbezüglich verschiedene orationes, die er der Kongregation präsentierte und welche Mucanzio ebenfalls in seinem Tagebuch festhielt. In diesen Predigten wird deutlich, dass die zeremonielle Öffnung der Porta Santa theologisch die Geburt Christi bereits als Vorsehung des Kreuzes- und Messopfers aufführt. Die vita, veritas und via Christi werden dabei mit dem Heiligen Sakrament der Eucharistie gleichgesetzt. Dem Gläubigen wird mit der Öffnung der Porta Santa als Porta Iustitiae der Eintritt in das Reich der misericordia Domini gewährt, denn diese Barmherzigkeit Gottes stellt die „beständige Quelle“ des Sündenerlasses dar. ${ }^{626}$ In der Öffnung der Heiligen Pforte wird demnach bewusst das zeremonielle Verständnis einer intercessio des himmlisch zu verwirklichenden Heilsversprechens in der irdischen Fleischwerdung des Gotteswortes betont. Deshalb führt Francesco Curtio eine weitere oratio auf, die der Gottesmutter als Gottesgebärerin gewidmet ist. In dieser oratio wird ein zum Eintritt in das Himmelreich der Barmherzigkeit entgegengesetzte Fluss des „herabsteigenden Heils“ (salutem descendere) angesprochen. Der Kanoni-

624 BAV, Chig.L.II.30, f. 267r-270r, bes. f. 267r-v, $268 v$.

625 BAV, Chig.L.II.30, f. 269v: Ex quibus quidem facile apparet in quibus diferant inter se dicti Versiculi, et oratio. Sed ut dixi resolutum fuit, ut dicerentur pro ut tempore Julij 3i. Verum post huius modi resolutionem factum R. D. Curtius Francus Canonicus Basilicae S. Petri vir prius, et in rebus sacris versatus ostendit mihi quasdam oratione à se ipso accomodatas ad hunc actum [...]. Curtio wurde nach seiner Beteiligung an der Herausgabe von Sirletos neuem Breviarum Romanum auch Rektor der römischen Casa dei Catecumeni. Vgl. hierzu seine Briefkorrespondenz mit Sirleto in BAV, Vat. lat. 6194, I, f. 29r, 33r, 53r, 63r, 104r, 122r, 164r, 263r \& 339r, in denen sich Curtio hauptsächlich mit der Frage auseinandersetzt, ob den Neophyten und Juden Roms sowohl an Ostern als auch Pfingsten die Taufe gespendet werden sollte. Curtio hatte ebenfalls seit 1566 engen Kontakt mit Carlo Borromeo gehabt, zumal Borromeo auch das Kanonikat von Santa Maria Maggiore innehatte. Vgl. hierzu die Briefkorrespondenz in BAM, F 37inf., f. 328r-329v, 337r-v, 340r-v, 459r-460v.

626 BAV, Chig.L.II.30, f. 270v: Domine Iesu Christe fili Dei vivi qui es via, veritas, et vita, qui dixisti ego sum ostium, per me si quis introierit salvabitur, et pascua inveniet, et iterm petite, et accipietis, pulsate, et aperiet nabis petentibus quae sumus desiderata concede, et pulsantibus hostium pande ac cunctarum veniam largire culpae. Aperi eis Domine Portas Iustitiae et ingressis in eas aperi eis misericordiae tuae fontem perennem; ut sicut nos hodie licet indigni sed Beati Apostoli tui meritis confisi et auctoritate, cum etiam dicere voluisti: quodcumq. ligaveris super terram, erit ligatum et in Celis et qodcumq. solveris super terram erit solutum et in Celis. 
ker Curtio begreift damit das anno santo als ein Ereignis, während dem die Gläubigen an die limina Apostolorum geführt werden. ${ }^{627}$

Während des Jubeljahres wird das zeitlose Himmelreich Christi in einen temporal begrenzten Zeitraum verwandelt. Damit wird den Gläubigen die Vergabe ihrer Sünden gewährleistet. Im Jubeljahr 1575 nahm Rom die Gestalt der Roma Sancta an. Francesco Mucanzios Einträge in seinem Zeremonialtagebuch deuten unter anderem darauf hin, dass Rom nicht erst zum Zeitpunkt des anno santo zu einer heiligen Landschaft umgewandelt wurde. Rom blieb stets die Landschaft des Heils. Allerdings konnte dieses versprochene Heil erst im Jubeljahr mit Hilfe des Sündenerlasses eingelöst werden. Dadurch wird die Stadt zur Heilslandschaft schlechthin. Dieses eindrückliche Erscheinungsbild Roms, in welchem die Stadt einem himmlischen Jerusalem geglichen habe, hielt der englische Pilger Gregory Martin in seinem Tagebuch folgendermassen fest:

[...] it were a thing much to be wished, that, as the Isräelites were bound to appeare thrise a yeere in Jerusalem, so al good Christians that may conveniently, once at the lest within xxv yeeres, did see with their owne eies this blessed Citie: But because there be many impediments, the next is to heare of it as a spectacle of fayth \& good workes, \& so to looke upon it far of, as upon a Citie set upon a hil that cannot be hid. According to Theodoretus writeth therof The Apostles tumbes give light to the whole world: and the Apostle him self testified of the first Christians there, that their faith was spoken of throughout the whole world. ${ }^{628}$

Im Zeremoniell des Jubeljahres wird somit das christliche Heilsgeschehen im Rom Gregors XIII. besonders betont. Die von den Mitgliedern der Zeremonialkongregation ausgearbeiteten Vorbereitungen zum anno santo ermöglichten diese besondere Artikulation, indem unterschiedliche officia miteinander verbunden wurden. Dabei bedienten sich die Mitglieder dieser Kongregation bewusst einer bereits im ambrosianischen Ritus vorzufindenden Liturgie. Das Ziel der Kongregation war es vorerst, den poenitentiarii der vier Patriarchalbasiliken Roms einen ebenbürtigen Platz innerhalb der zeremoniellen Feier der Öffnung der Porta Santa zuzuweisen. ${ }^{629}$ Die Mitglieder der Zeremonialkongregation sahen im Kurienzeremoniell eine Möglich-

627 BAV, Chig.L.II.30, f. 271r-v: Deus qui de B. Mariae Virginis euxoro Unigentum filium tuum, tamquam Sponsum de thalamo à summo coelo egressum, ad haec infima propter nos, et propter nostram salutem descendere voluisti, et Mundo in tenebris, et in umbra mortis sedenti immortalitatis tuae aditum devicta morte reservati vota nostra quae praeveniendo aspiras adimando prosequere, ut omnes qui hoc Sancto Iubilei anno ad Apostolorum tuorum limina pervenerint, eos meritis, et intercessione post huius vitae exitum Paradisi ianuas introire mereantur.

628 Martin, Roma Sancta, S. 8.

629 BAV, Chig.L.II.30, f. 273v-274r: Pentitantiarij ecclesiae quattuor cum totidem Malleis percutient, et rumpent penitus Portam adiuvantibus fabris, non tamen intrant ipsam Portam. [...] Deinde Pentintentiarij ladabunt postes praedicte Portae hinc inde aqua benedicta, ibi prius in Vase magno praeparata, et Mappis abstergent. Cantores dum praedicta fiunt cantabunt Psalmum Iubilae Deo et Psalmum laudate Dominum Sanctis eius et Psalmum Laudate Dominum omnes gentes, repetendo si opus erit. 
keit danach, das Caeremoniale Romanae Curiae mit den rituellen Vorschriften aus der römischen Liturgie abzugleichen. Dieser Abgleich war ursprünglich für ein Rituale Romanum vorgesehen. Da aber ein solches Rituale zum Zeitpunkt des Jubeljahres weder überarbeitet noch druckreif vorlag, wurde das Kurienzeremoniell zum anno santo für eine rituellen Neuregulierung der Kurie in Betracht gezogen. Francesco Mucanzios Aufzeichnungen in seinem Zeremonialtagebuch widerspiegeln ebenfalls diese von der Zeremonialkongregation beschlossenen rituellen Anordnungen. So vollzog beispielsweise der Papst, gekrönt mit der Mitra und nicht mit der Tiara, den rituellen Akt der zeremoniellen Eröffnung des Jubeljahres. Damit wurden dem Papstamt die munera des priesterlichen Vollzugs, die den munera pastoralia Carlo Borromeos entsprachen, zugeschrieben. Der Papst wurde dadurch zum alleinigen Verwalter des göttlichen Sünden- sowie Gnadenerlasses erklärt.

Das Zeremoniell zum anno santo orientierte sich demnach hauptsächlich an der bereits von Borromeo vertretenen Vorstellung, jeden Gläubigen mit Hilfe eines spezifischen Ritus „zu bewegen und zu rühren“, um ihnen damit das christliche Heilsversprechen auch liturgisch offenbaren zu können. Der Ritus des Durchschreitens der geöffneten Heiligen Pforte und der damit verbundene Eintritt in das verzeitlichte Gnadenreich Gottes wird mit dem prophetischen „Einherschreiten des Fastens“ gleichgesetzt. In seiner De rhetorica ecclesiastica hielt Agostino Valier diesen Ritus als ein officium praedicandis fest, mit Hilfe dessen die Busse als virtus christianarum ausgelegt wurde. ${ }^{630}$ An dieser Stelle muss zuerst die Frage beantwortet wer-

630 Valier, De rhetorica ecclesiastica, II.15, S. 102: Poenitentiae pars et virtutum christianarum parens ac custos est ieiunium. Quare ostendat ecclesiasticus orator ieiunium ad iram Dei placandam et peccata expianda, saepe etiam ad impetrandum aliquid a Deo adhibitum fuisse. Ninvitas, auditis illis verbis: 'Adhuc quadraginta dies et Nineve subvertetur' (Jh 3, 4-7) illico ad ieiunium universos confugisse ubique saccum, ubique cinerem, fuisse ubique fletum et eiulatum auditum ac propterea e tantis periculis illos ereptos fuisse, Moysem (Ex 34, 28) et Eliam si quando ad Deum volebant accedere et, quantum homini fas est, eum alloqui, a ieiunio open petiisse, Danielem leonum lacum ieiunium ingredientem, mitem ab immitibus illaesum rediisse, tres pueros apud Babyloniam caminum ingressos atque in igne laudantes Deum egressos [...] Quod si Deus hominem a principio condens in Paradiso eum ieiunii lege voluit cohibere cum dixit: 'De omni ligno Paradisi comede, de ligno autem scientiae boni et mali ne comedas' (Gen 2,16), multo magis illud extra Paradisum necessarium putandum est [...]. Zur Priorisierung des modus commoviendi vgl. Battistini 2007, S. 31-43; Valier, De rhetorica ecclesiastica, II.4, S. 89-90. Welche Auswirkung Valiers Abhandlung auf die Traktatliteratur der artes praedicandi im Europa des 16. Jahrhunderts hatte, zeigen die beiden 1576 in Lissabon und Salamanca erschienenen Werke des Dominikaners Luis de Granada (Ecclesiasticae rhetoricae sive de concionando libri sex) und des Franziskaners Diego Estella (Modus concionandi). Im Zusammenhang mit Valiers Verständnis des modus concionandi vgl. daher auch Estella, Modo de predicar, I, S. 165-181, 188-205, und Granada, Ecclesiasticae rhetorica, II/1, S. 32-33: Quid sit Rhetorica, quae eius materia, quod officium et finis, et quae sin eius partes. An Granadas Traktat bediente sich allen voran Borromeo für die Vorbereitungen seiner Predigten. Vgl. hierzu Giombi 1997, S. 75; Fumaroli 1994, S. 148-156; Patrizi 2017, S. 270-271, sowie die beiden Briefe Valiers an Borromeo vom 13. und 27. Dezember 1577 in BAM, F 50inf., f. 98r-v, 450r, 469v. 
den, wie der Mailänder Bischof Carlo Borromeo die Pflege des ambrosianischen Ritus in seiner eigenen Diözese verwaltet hatte. Denn nach dem anno santo sollte sich dieser Ritus zunehmend gegensätzlich zu den liturgisch-zeremoniellen Vorstellungen der Kurie entwickeln. In einem am 25. Januar 1575 erlassenen und an Borromeo adressierten breve, in welchem Gregor XIII. die antiquitas des ambrosianischen Ritus lobte, bevollmächtigte der Boncompagni-Papst den Mailänder Bischof damit, diesen Ritus auf alle Kirchen und Klöster der Diözese Mailands zu übertragen. ${ }^{631}$ Seine Weihe zum Bischof von Mailand, die ihm Papst Pius IV. am 7. Dezember 1563 verliehen hatte, verstand Carlo Borromeo nicht nur als blosse Nachahmung des Kirchenvaters Ambrosius. Auch sein Episkopat sowie seine Diözese wollte Borromeo bewusst gemäss einer Tradition der bischöflichen Diözesanadministration, deren Ursprünge auf den Kirchenvater zurückgingen, verwalten. ${ }^{632}$ Borromeo liess diese Eintracht zwischen seinem Bischofsamt und dem Kirchenvater Mailands in den Druck liturgischer Bücher einfliessen. Zur erfolgreichen Bewältigung dieser Aufgabe setzte Borromeo ab 1574 in Mailand eine eigenständige Congregazione del Rito Ambrosiano ein, deren Gründung sein Biograph Guissano in seiner Biographie des Kardinalbischofs folgendermassen schilderte:

631 Sala, Documenti, I, S. 296: Ecclesiae Mediolanensis, cui ex dispensatione apostolica prae es, peculiaris ac propria in divinis officiis ac ritibus ratio, cum non modo ducentis ab hinc annis introducta, sed usque adeo antiqua sit, ut jam inde ab ipso beato Ambrosio confessore et doctore instituta atque praescripta perpetuo sit catholicae Romanae Ecclesiae firmata consensu, nos propterea, quoniam tu pro eo, quod debes, in eam curam incumbis, ut ista tua Ecclesia non conservetur solum, sed restituantur veteres ritus, et antiqua illa Ambrosiani officii institutio, eaque ipsa jamdiu probata in dioecesis tuae Ecclesiis una eademque certa servetur [...]. Vgl. auch die im Oktober 1574 genehmigte Erlaubnis, seine Diözese während des Jubeljahres verlassen zu dürfen, in ibid., S. 294: Cum annus Jubilei a nobis indicti jam appropinquet, non dubitamus te pro tua eximia pietate magno desiderio teneri eo potissimum tempore visitandi apostolica limina, caeterasque almae Urbis Basilicas, ut sanctorum reliquiis venerandis, in quibus Christus ipse vixit, illius etiam coelestis thesauri particeps sis, quem Sanctorum merita ex Christi Domini plenitude cumularunt. Sed neque illud nobis obscurum est, qui tuam pastoralem diligentiam perspectam habemus, te quidem quantum devotionis zelo ad hoc iter ineundum impelleris, tantum vicissim istus Ecclesiae tuae deserendae sollicitudine retardari, ad cujus custodiam ita tibi ex Tridentini Concilii praescripto, perpetuo excubandum, vigilandumque esse intelligis, ut inde injussu nostro ne ad breve quidem tempus recedendum putes.

632 AEM (1890-1897), II, Sp. 1146-1147: [...] ritum praecipuum, atque eum quidem antiquissimum [...] quem a sancto Ambrosio patre patronoque nostro institutum, et a beato Simpliciano auctum, deinceps archiepiscopi, qui ordine successerunt, tamquam amplam sibi haereditatem relictam, religiose conservarunt. Beide Biographen Borromeos, Antonio Possevino und der Barnabit Carlo Bascapè, erinnern sich, dass Borromeo selbst bei den Feierlichkeiten zur zweiten Provinzialsynode im Mailänder Dom eine Messzelebration nach römischen Direktiven verboten hatte. Vgl. hierzu Possevino, Discorsi, S. 223; Bascapè, De vita et rebus gestis, S. 29. Guissano berichtet sogar - wie im Übrigen auch Bascapè -, dass Borromeo sich dem Vorbild des Kirchenvaters Ambrosius in dem Masse annäherte, dass er gar bereit gewesen wäre, auf die Kardinalswürde zu verzichten, damit er Mailand nicht verlassen müsse. Vgl. Guissano, Vita, S. 364. 
Dopo molte fatiche, che il B. Pastore fece il presente anno nella visita della sua Chiesa, celebrò poi anche il Quarto Concilio Diocesano; mà fece prima una Congregatione de' suoi Ministri, \& Vicarij Foranei, che durò tre settimane; nella quale volle da essi primieramente informatione del frutto, che operato havevano i decreti de' Concilij passati, e le visite fatte; e che impedimenti si ritrovavano nella loro essecutione. Dipoi fece una raccolta di tutti gl'abusi, che vi erano, con i rimedi per levarli; e finalmente trattò di riformare il Rituale Ambrosiano, col Messale, e Breviario. Per mezo di questa Congregatione egli restò informatissimo di tutto lo stato della sua Chiesa, e notò i bisogni, con le opportune provisioni; che fù una buona preparatione per celebrare il Concilio, con gran frutto, come fece poi il giorno 16 di Novembre dell'istesso anno $1574 .{ }^{633}$

Antonio Possevino und Carlo Bascapè hielten ebenfalls in ihren Biographien Borromeos fest, dass es das Ziel dieser Kongregation - und mithin auch Borromeos war, die Beständigkeit des ambrosianischen Ritus und seiner Liturgie nachweisen $\mathrm{zu}$ wollen. In erster Linie sollte dadurch gezeigt werden, dass der ambrosianische Ritus eigene und vom römischen Ritus unabhängige officia besass. ${ }^{634}$ Die grosse

633 Guissano, Vita, S. 224-225, hier 224. Bereits im selben Jahr ihrer Einberufung gab die Kongregation ein neues Psalterium heraus. Zur Arbeitsweise der mailändischen Kongregation vgl. insbes. AEM, II, Sp. 1633-1635, sowie hinsichtlich der Mitarbeiter Borromeos dann Cattaneo 1943, S. 90-102. Die wichtigsten Mitarbeiter dieser Kongregation waren Pietro Gallesini, der Kardinal Guglielmo Sirleto, der Barnabit Carlo Bascapè, der maestro delle sacre cerimonie, Giovanni Paolo Clerici, sowie Rodolfo della Croce, der primicerius des Domkapitels war. Für die Herausgabe eines überarbeiteten Breviarium Ambrosianum war Galesini stark auf eine Kollaboration mit Kardinal Sirleto angewiesen, die nicht nur aus seiner Briefkorrespondenz mit dem Vorsteher der Indexkongregation entnommen werden kann, sondern sich auch aus dem Austausch zwischen Sirleto und Borromeo selbst ergab. Aus diesen Briefschreiben geht hervor, dass die Druckgenehmigung des Breviarium unmittelbar nach der Herausgabe eines neuen Psalterium geschehen sollte. Vgl. hierzu die Briefe Galesinis an Sirleto zwischen 1570 und 1571 in BAV, Vat. lat. 6184, I, f. 57r-v; BAV, Reg. lat. 2023, f. 179r; BAV, Vat. lat. 6191, f. 26v-27r; BAM, F 43inf., f. 309r. Eine wichtige Grundlage für die Revisionsarbeiten dieser Kongregation boten dabei die von Pietro Gallesini im Auftrag Borromeos zusammengestellten vitae Mailänder Bischöfe. An dieser Zusammenstellung von Bischöfen war auch der Kardinal und Bischof von Bologna Gabriele Paletti sehr interessiert. Vgl. hierzu die Briefkorrespondenz Galesinis mit Borromeo in BAM, F 49inf., f. 170r, sowie ein Briefschreiben Galesinis an Sirleto vom 4. April 1570 in BAV, Vat. lat. 6190, f. 343r. Borromeo berichtete Paleotti in seinem Briefschreiben vom 13. Februar 1572, in BAM, P 7inf., f. 94r, über den Fortschritt dieser Arbeiten. Vgl. dann auch sowohl den Katalog der Bischöfe als auch den Beschluss der dritten Provinzialsynode Mailands über die Wichtigkeit der res gestae episcoporum in AEM (1890-1897), II, Sp. 278, 381-401.

634 Bascapè, De vita et rebus gestis, S. 336-337: Cum ad corrigenda librorum ecclesiasticorum menda, quae superiorum temporum vitio irrepserant, aggregeretur; quae quidem fuit eius non postrema cura; fuere qui suaderet, ut eo labore omisso, romanos potius eligeret, et in Ecclesiam suam introduceret. Quod ille sibi in tantae antiquitatis, auctoritatisque institutis, neque ex toto neque ex parte faciendum; neque aptam eiusmodi Ecclesiae varietatem, quam sancti patres probassent, sibi tollendam constituit. Num proposuerunt etiam quidam, ut quia primam Quadragesimae dominicam restituerat, quatuor quoque alios dies ex communi consuetudine curare addi; ille vero ritus Ecclesiae suae restituendos, non autem mutandos affirmabat. Vgl. auch Possevino, Discorsi, S. 221-222: „La Chiesa Ambrosiana già molti e molti anni ha goduto questo privilegio concessoli dalla Romana, di 
Schwierigkeit, mit der Borromeo und die Mitglieder der Mailänder Ritenkongregation bei ihren Arbeiten zu kämpfen hatten, war, den Nachweis einer Unveränderlichkeit der zeremoniellen Rahmenbedingungen, die für den rituellen Vollzug der ambrosianischen Liturgie gedacht waren, zu erbringen. Die Mailänder Ritenkongregation stellte sich dabei den ambrosianischen Ritus in seiner tertullianischen Maxime des Christus sponsus Ecclesiae vor. Mit diesem Grundsatz wurde im mailändischen Zeremoniell der in Christus eingeprägte logos mit der Kirche als sichtbare Hülle liturgisch verbunden. ${ }^{635}$ Damit wurde aber zwangsläufig vorausgesetzt, dass beim rituellen Vollzug dieser Fleischwerdung des Gotteswortes die sichtbare Hülle keine Veränderungen erfuhr.

Indem Carlo Borromeos Ritenkongregation in Mailand eine derartig konzentrierte Verschmelzung der Theologie des Gotteswortes mit ihren zeremoniellen Bedingungen vorzulegen im Stande war, muss sie im Hinblick auf das anno santo in Rom für die Kurie eine geeignete Grundlage dargeboten haben. Die Devise des Kirchenvaters Tertullian der sponsae Eccleisae sollte allerdings den Bedingungen des römischen Stadtraumes im Verlaufe des Jubeljahres noch angepasst werden. Diese Angleichung sollte dann dazu führen, dass der rituell vollzogene Sündenerlass für alle Patriarchalbasiliken umfassend gültig war. Erst dadurch konnte die Kurie ihren ekklesiologischen Anspruch auf die Verwaltung aller Sakramente im Messritus erheben. Demgemäss musste Roms urbane Topographie einer spezifischen Form der rituellen Sakramentsverwaltung angepasst werden, da sich in dieser Verwaltung die alle vier Hauptkirchen Roms umfassende Ecclesia als Braut Christi artikulieren sollte. Wie entfaltete sich also im Stadtraum eine spezifisch römische Ausprägung dieses rituell-liturgischen Verständnisses, das ebenfalls in das Kurienzeremoniell einfloss?

\subsection{Sichtbarkeitsdynamiken der pietas}

Im rituellen Vollzug der ambrosianischen Liturgie wird anhand des Verständnisses der Kirche als Braut Christi eine Identität zwischen dem sich im Kirchengebäude

cui essa è uno de principali membri e nobili figlie, di havere certe cerimonie separate e riti, sì nel dire la santa Messa, come nel celebrare e recitare i Divini officij, amministrare i Santissimi Sacramenti, \& altre simili cose che troppo sarebbe lunga e sorvechia cosa il volere quì descriverle. Maggior parte di questi riti fù introdotta da quello che fù sì grande esempio di tutti i Pastori, e sì forte degno Vescovo Ambrosio santo. [...] Carlo come fù ardentissimo di restituire tutta l'Ecclesiastica disciplina [...] così messe studio grandissimo in reformare e reintrodurre tutti i sopradetti riti della Chiesa sua con tanta maiestà [...].“

635 Tertullian, De ieunio adversus psychicos, in: CSEL 1890, Bd. 20, S. 275. Am deutlichsten kam diese Richtlinie in einer am 4. Dezember 1583 in Bellinzona gehaltenen Homilie zum Ausdruck. Vgl. Borromeo, Homiliae, I, S. 117; Valier, Vita, S. 44-45; Possevino, Discorsi, S. 73-74; Bascapè, De vita et rebus gestis, S. 335-338. Für den magister caeremoniarum erliess Borromeo ebenfalls eine Reihe von Bestimmungen hinsichtlich der Messefeiern, die im Duomo zelebriert werden sollten. Diese finden sich in AEM (1890-1897), III, Sp. 1239-1253 zusammengestellt. 
verwirklichenden Heilsversprechen Christi und dem mysterium der Fleischwerdung Gottes geschaffen. Diese theologische Eintracht liess sich für den Mailänder Bischof Carlo Borromeo somit im Kirchenraum selbst realisieren. Dieser Kerngedanke bereitete eine der wichtigsten Grundlage für seine bereits erwähnten Instructiones, die zwei Jahre nach dem anno santo erschienen. Die rituellen Arbeiten der Mailänder Ritenkongregation veranlassten einen Wettlauf zwischen Mailand und der Kurie um die liturgische Vormachtstellung des ambrosianischen Zeremoniells. Dieser Streit zwischen ambrosianischem und römischem Ritus sollte allerdings zu Gunsten der Kurie ausgehen und den Vorrang eines römischen Verständnisses der sakramentalen Verwaltungspraxis bestätigen. Im Gegensatz zu Carlo Borromeo konzipierten die Mitglieder der kurialen Zeremonialkongregation den rituellen Vollzug sakramentaler Liturgie so, dass er auch ausserhalb des Kirchenbaus Anwendung finden sollte. Das römische Verständnis der sakramentalen Verwaltungspraxis besass nämlich nur dann eine Allgemeingültigkeit, wenn deren liturgischen Voraussetzungen auch auf den gesamten Stadtraum Roms angewendet werden konnten. In der zur Roma Sancta verwandelten Stadt begann man allmählich damit, das Heilsversprechen Christi und dessen Erfüllung anhand der von den Patriarchalbasiliken Roms vorgegebenen Bedingungen einzuordnen. Das Kurienzeremoniell des anno santo gab jedem Rombesucher die Stadt als ein Himmlisches Jerusalem preis, das aber nur für eine bestimmte Zeit - nämlich ein Jahr - aufgeschlossen war. Der städtische Raum wurde damit einem Wandel unterzogen, durch den die christliche pietas einen neuen, zentralen Stellenwert zugeordnet bekam. Damit konnte ein Kurienzeremoniell gewährleistet werden, das die gesamte Stadt erfassen konnte.

Im Rom des Jubeljahres 1575 manifestierte sich eine spezifische Idee der Frömmigkeit, die mit der für das Zeremoniell wichtigen Theologie der caritas übereinstimmte. Diese Übereinstimmung von pietas und caritas wurde besonders in der Bildproduktion von Kupferstichen während des Boncompagni-Pontifikates sichtbar bewerkstelligt. Solche anlässlich des Jubeljahres angefertigten Stiche stifteten zugleich ein einheitliches Bild der Romana Ecclesia. Seit Lucien Febvre die Vorstellung einer „Laienfrömmigkeit“ einführte, vernachlässigte die Forschung sowohl die Theologie der Frömmigkeit aus Sicht der Kurie als auch die damit verbundene Bildimmanenz, die der pietas zu Grunde liegt, genauer zu untersuchen. ${ }^{636}$

Mit der karitativen Fürsorge römischer Bruderschaften wurde die caritas den Bedingungen der Stadt Rom angepasst. Insbesondere die Frömmigkeitspraktiken der Oratorianer von San Giovanni dei Fiorentini überschnitten sich dabei mit kurialen Ausgestaltungen eines neuen Zeremoniells für das anno santo. Germanico Fedeli erinnert sich in seiner späteren Zeugenaussage zum Heiligsprechungsprozess Filippo Neris daran, welche atti di carità Neri selbst in Rom ausübte:

636 Febvre 1929, S. 1-29; idem 1957, S. 1-70; Burke 1972, S. 44-107; idem 1988, S. 113-114; O’Malley 2000, S. 95; Fenlon 1971, S. 67. 
[...] esercitava atti di carità, non solo negli bisogni spirituali dell'anime, ma anco nelli bisogni et necessità corporali, come mostrò nell'andare spesso all'hospedale di Roma, menando seco alcuni suoi figlioli spirituali, insieme con li quali dava a mangiare a quelli infermi, portandogli anco, alcuna cosa di conforto et di ristoro et servendogli altre necessità, secondo il bisogno. ${ }^{637}$

In der caritas werden die geistigen Bedürfnisse der Gläubigen mit den körperlichen Begehren verbunden. An diesen bisogni sollte sich folglich die bereits angesprochene Theologie der Genugtuung in der sakramentalen Verwaltung der Busse orientieren. Dadurch wird im Sündenerlass eine Identität zwischen den Werken der Wohltätigkeit und der göttlichen Gnadengewährung geschaffen. Diese Übereinstimmung fand der englische Pilger Gregory Martin hauptsächlich in den montes pietatis verkörpert. Mit der Bulle Ad sacram Beati Petri sedem wurde die Verwaltung dieser monti di pietà im Farnese-Pontifikat Pauls III. einer eigens dafür einberufenen Bruderschaft anvertraut. In der am 5. April 1576 erlassenen Papstbulle erneuerte Gregor XIII. die Zugeständnisse, welche Pius IV. dieser Bruderschaft gemacht hatte. Diese Konzessionen erlaubten es der Bruderschaft, römische Juden aufnehmen zu dürfen. Den in die Bruderschaft aufgenommenen Juden war es unter bestimmten Voraussetzungen ferner erlaubt, die von der Bruderschaft verwalteten Kredite vergeben zu dürfen. ${ }^{638}$ Diese monti di pietà Roms, die bislang in der Stadtgesellschaft als Verkörperung der Lasterhaftigkeit und des Zinswuchers schlechthin angesehen wurden, begannen nun die caritas zu fördern. Die Gewährleistung von Kreditaufnahmen war nach der vollständigen Rückzahlung der Geldschuld mit einem päpstlich bewilligten Ablass verbunden:

[...] The incident almes he geveth in this sort upon diverse, are manifold, and knowen rather to a fewe necessarie partie, then to the world. For example, when a noble familie was fallen into povertie, this Pope gave to sixe children remayning thereof, so many Montes, that is, so many annuities to continewe for theyr sufficient mayntenance. ${ }^{639}$

637 Primo Processo, III, S. 262-263. Vgl. auch Marciano, Memorie historiche della Congregazione, S. 525. Vgl. dann die weiteren Zeugenaussagen zu Neris Praxis der caritas in ibid., II, S. 292 (Baronio); I, S. 22 (S. Grazzini), S. 29 (M. Zazzara), S. 135 (F. Cardoni); ibid., III, S. 389 (D. Corvesi). Zusammenfassend hierzu Bella 2006, S. 182-186. Für das anno santo ist vor allem Neris Bekanntschaft mit dem später zum Heiligen gesprochenen Camillo De Lellis zentral. De Lellis gründete aus dieser Bekanntschaft mit Neri seine Compagnia di carità. Vgl. hierzu Vanti 1929, S. 59, 62-64; Cicatelli, Vita, S. 19-23. Camillo De Lellis spielte in der Ausgestaltung eines officium proprium für die Geburt der Gottesmutter, dessen wichtigster Programmgestalter Cesare Baronio war, ebenfalls eine zentrale Rolle.

638 Die päpstliche Bulle und die zugesprochenen Konzessionen wurden in die durch die Druckerei der Camera Apostolica vorgelegten Statuti del Sacro Monte di Pietà di Roma, hier S. 58-60, aufgenommen. Vgl. auch Martin, Roma Sancta, S. 132-133, sowie dann den in die Tridentiner Reformdekrete der 22. Sitzung aufgenommenen Kanon über die Habsucht in COD, S. 741. Zur Entwicklung der monti di pietà im Rom des Cinquecento vgl. jüngst Arcelli 2003; Carta 2000, S. 65-76; Esposito 2003, S. 559-582; eadem 2017, S. 399-400.

639 Martin, Roma Sancta, S. 107-108. 
Solche „Orte der Frömmigkeit“ wirkten im römischen Stadtraum als Behörden der pietas, mit der eine Theologie der caritas eng verzahnt war. Im römischen Stadtraum wurde damit Frömmigkeit mit Nächstenliebe gleichgesetzt, sodass die monti di pietà auch zu Gunsten der Verwaltungspraxis der poenitentia instrumentalisiert werden konnten, weil dadurch ferner eine Identität zwischen Ecclesia und caritas/pietas erzeugt werden konnte. Die theologische Betonung lag demnach auf der mystischen Ehe (matrymonium) zwischen Ecclesia und Christus, die den göttlichen Sünden- und Gnadenerlass überhaupt ermöglichte. Anhand einer von der Forschung erst seit kurzem beachteten Serie von Stichen, die anlässlich des anno santo für den major poenitentiarius Stanislaus Hosius hergestellt wurde, kann festgestellt werden, dass die Apostolische Pönitentiarie diese römische Eintracht zwischen Ecclesia und caritas auch in bildproduktiver Hinsicht zu realisieren bestrebt war. In seinem Briefschreiben vom 11. Oktober 1575 an Carlo Borromeo teilte Stanislaus Hosius dem Mailänder Bischof mit, dass jemand aus seinem Haushalt die Ecclesia zwei Jahre zuvor und das Kreuz 1574 dargestellt habe. Dieselbe Person arbeite nun an einem Stich, der die Roma Sancta repräsentieren sollte. ${ }^{640}$ Das Briefschreiben bezog sich demgemäss auf die zwischen 1573 und 1575 vom polnischen Prälaten Tomasz Treter ausgeführte Stichserie der Typus Ecclesiae Catholicae, der Allegorie des Kreuzes und der Roma Sancta (Abb. 19a \& 19b).

Diese im Haushalt des Kardinalspönitentiars Hosius entstandene Stichserie wurde dann vom Kupferstecher Giovanni Battista de“ Cavalieri während des Jubeljahres übernommen. Zwischen 1569 und 1593 hielt sich der polnische ecclesiasticus Treter selber in Rom auf. Dort übernahm er ab 1578 das Kanonikat von Santa Maria in Trastevere, der Titelkirche des Ermländer Bischofs Stanislaus Hosius. Derselbe Treter trug auch die Leichenrede für den am 9. August 1579 verstorbenen Kardinal Hosius vor. Zusammen mit Hosius' Sekretär Stanislao Rescio sorgte er sich schliesslich um das langanhaltende Nachleben des major poenitentiarius. ${ }^{641}$ In dieser für Kardinal Hosius hergestellten Stichserie suchte Treter nach einer geeigneten bildschematischen Übersetzung allegorischer Vorstellungen der Ecclesia, die den römischen Auffassungen sowohl über die pietas als auch über die Stadt selbst entsprach. Treter hielt in einer Inschrift seines ersten Stiches, das den Typus Ecclesiae Catholicae

640 BAM, F 74inf., f. 218r. Am 20. Mai 1573 teilte Hosius Borromeo bereits mit, dass der erste Stich fertiggestellt sei, in BAM, F 91inf., f. 59r. Zu dieser Stichserie vgl. v. a. Chrzanowski 1981, S. 243254; Jurkowlaniec 2012, S. 130-150; Gallori 2013, S. 238-265.

641 Treters oratio funeralis für den verstorbenen Kardinal wurden in Rescius, Stanislaus Hosii vita, S. 329-399 1587, aufgenommen. Treter liess ebenfalls seine Theatrum virtutum Stanislai Hosii 1588 in Rom drucken, die eine Sammlung symbolischer Darstellungen der Biographie des Kardinals enthalten. Auch war der polnische Kanoniker zuständig für die zeichnerische Konzeption von Hosius' Grabmalmonument in Santa Maria in Trastevere und sehr wahrscheinlich auch für das Grabmal der Königin von Polen, Bona Sforza (1494-1557), welches in der Kathedrale in Bari errichtet wurde. Zum Grabmal in Rom vgl. insbes. Jurkowlaniec 2009, S. 69-98; eadem 2006, S. 228-230. Zu demjenigen in Bari dann Waźbiński 1979, S. 59-86; Mongelli 1984, S. 57-79; Cioffari 2000, S. 348-355. 


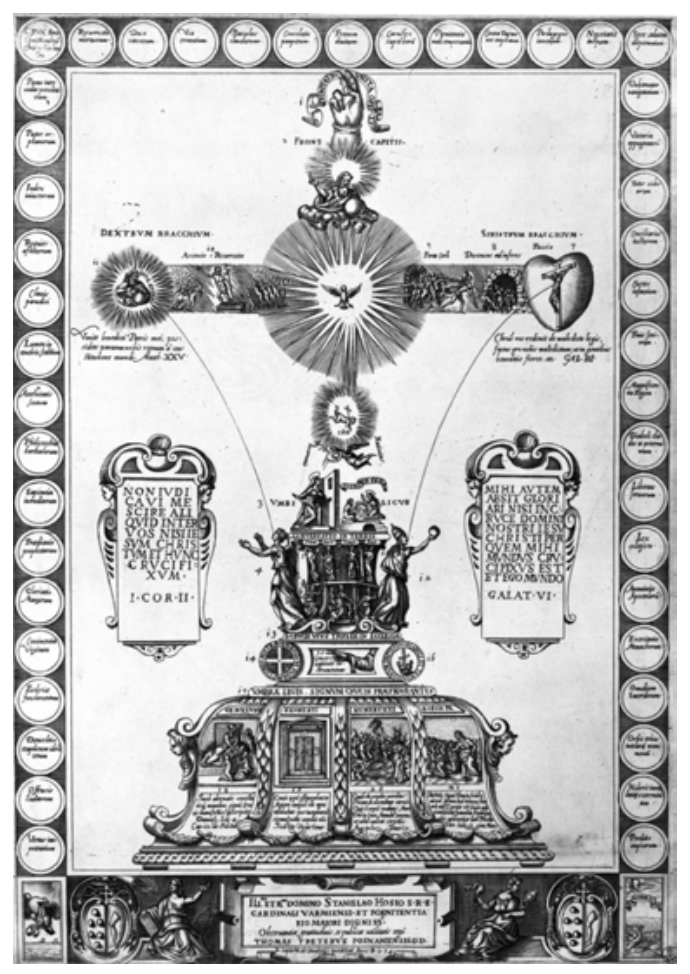

Abb. 19b: Giovanni Battista de' Cavalieri, nach Tomasz Treter, Allegorie des Kreuzes, Kupferstich, 1574, Gabinetto Disegni e Stampe degli Uffizi, Florenz.

zeigte, fest, dass nach dessen Erscheinen Stanislao Rescios Explicatio typi Ecclesiae ebenfalls 1573 erschienen sei. Ein Jahr später legte derselbe Rescio dem major poenitentiarius eine italienische Erklärung seines Werkes vor, die in Antonio Blados Druckerei erschien. Rescios Explicatio wurde dann 1574 in Venedig durch Luca Bertelli gedruckt. ${ }^{62}$ Bertelli hatte dieser gedruckten Fassung von Rescios Explicatio einen eingerahmten Stich, der sich leicht von dem Treters aus dem Jahr 1573 unterscheidet, beigefügt. Den ersten Stich des polnischen Kanonikers, der mittels einer in Madrid aufbewahrten Kopie ebenfalls Stanislaus Hosius gewidmet war, reproduzierte der Trienter Kupferstecher Giovanni Battista de‘ Cavalieri 1574. 1595 folgte eine zweite, verbesserte Version desselben Bildmotivs.

Tomasz Treters Typus Ecclesiae Catholicae zeigt in der Mitte des oberen Bildabschnitts auf der Zentralachse des Blattes den Kopf Gottvaters, ein Kruzifix und eine Taube des Heiligen Geistes. Auf der horizontalen Achse im oberen Drittel des Stiches sind mit dem gekreuzigten Christus zwei vom Kreuz getrennte Gruppen heiliger

642 Jurkowlaniec 2012, S. 131-132. 
Apostel dargestellt, die auf Wolken sitzen und sich dem Kreuzes- und Messopfer zuwenden. Der untere Abschnitt zeigt eine komplexe Allegorie der Kirche, in der verschiedene Kettenstränge zusammengeführt werden. Diese Darstellung der Kirche betont den architektonischen Gesamtbau der Sakramente im Kirchenkörper der Sancta Ecclesia. Die sieben Sakramente werden entlang der beiden Bildränder präsentiert. Unterhalb der allegorischen Darstellung der Kirche ist eine zweigeschossige Tempelarchitektur zu sehen. Die Pfeiler auf ihrer Fassade tragen Skulpturen der zwölf Apostel. Treter hebt in seiner Bildlösung den Zusammenhang der sieben Sakramente, deren prominenteste Position das Sakrament der Taufe oberhalb der Sancta Ecclesia einnimmt, hervor. Damit beabsichtigt er zu zeigen, wie diese Siebenzahl der Sakramente mit ihrer himmlischen und kirchlich-irdischen Verwaltung zusammenhängt. Zwei der Ketten, die zu den beiden auf Wolken verteilten Aposteln führen, werden von zwei Tafeln begleitet. Die Inschriften auf diesen Tafeln bezeichnen die Sakramente als vasae gratiae und meritorum Christi. Einzig das Taufsakrament scheint nicht direkt über eine Kette mit der Sancta Ecclesia verbunden zu sein. Die Taufe ist das einzige der sieben Sakramente, das von Gott sowohl über das Kreuzes- und Messopfer Christi als auch über den Heiligen Geist gespendet wird. Indem es in einem Taufbecken aufbewahrt wird, vermittelt es in Treters Stich den göttlichen Fluss des Heils. Allein dem Priester (sacerdos) ist es gestattet, dieses Sakrament an diejenigen Gläubigen zu spenden, die sich dem Taufbecken nähern. ${ }^{643}$ Im Gegensatz zum Taufsakrament, von dem aus der weitere Fluss des Heils auf die anderen sechs Sakramente übergeleitet wird, hängen die übrigen Sakramente fest mit der Sancta Ecclesia zusammen. Es scheint, als ob in den begleitenden Szenen, in denen die Verwaltung der Sakramente gezeigt wird, immer wieder die Kirche selbst zum Ausdruck gebracht wird. In der Verwaltung der Sakramente wird die Sancta Ecclesia als ein Haus präsentiert, in welchem diese Sakramentsverwaltung rituell vollzogen wird. Die Szene der Taufe hingegen referiert eindeutig auf die biblische Episode der Taufe Christi, die nach dem Johannesevangelium im Jordan bei Bethanien stattfand (Jh 1, 28). Das Taufsakrament wird inmitten einer hügelartigen Landschaft gespendet, weshalb es damit auch eine Eigenständigkeit gegenüber der Kirchenarchitektur suggeriert.

In seinem ersten Stich setzte sich Tomasz Treter somit intensiv mit der Frage auseinander, wie der heilswirkende Gnadenflusses Gottes über die sieben mit der Sancta Ecclesia verbundenen Sakramente zirkuliert. Obwohl Treter den zweiten Stich dieser Serie, der eine Allegorie des Kreuzes zeigt, selbst entwarf, wurde dieser vom Trienter Kupferstecher Giovanni Battista de' Cavalieri ausgeführt. Der Stich stellt einen weiteren Typus der Kirche als Kreuz dar. Der Stich wird sowohl in der

643 Rescius, Explicatio, 20: [...] qui postea quam ad Baptismi fontem accessit, à Deo Patre, sanguine filij, per Spiritum sanctum, Sacerdotis ministerio, sanctificatur \& iustificatur: quae quidem sanctificatio, virtute Christi sanguinis, quem in calicem passionis manare vides, fidelibus contingit. 
Galleria Uffizi als auch in der Sammlung der Prinzen von Waldburg-Wolfegg aufbewahrt. ${ }^{644}$ Das christliche Heilsgeschehen ist in Cavalieris Bildaufbau der Allegorie nach der Form eines Kreuzes gegliedert. Damit wird auf das im Kreuzes- und Messopfer Christi präservierte Heilsversprechen verwiesen. Cavalieris Allegorie ist aber keineswegs anspruchsloser als der Bildaufbau im Typus Ecclesiae. Im Stich wird ein auf einem Altar aufgestelltes Kruzifix, das aus kleinen rotundeartigen Szenen zusammengesetzt ist, gezeigt. Die Reihenfolge der Rundszenen gestaltet die Form des Kreuzes. Die Bildlösung verbindet somit eine vertikale mit einer horizontalen Ebene narrativer Szenen. Die beiden Szenenstreifen treffen sich im Mittelpunkt des Kreuzes, wo die Taube des Heiligen Geistes leuchtend schwebt. Damit wurde bewusst auf einen zirkulierenden Gnadenfluss, wie er in Treters erstem Stich zu sehen war, verzichtet. Auf dem vertikalen Arm des Kreuzes ist im oberen Bildabschnitt die Hand Gottes, die einen gefalteten Schriftzug hält und auf welchem SANCTAE TRINITATE VNITA OPERATIO steht, aufgeführt. Über die Inschrift FRONS CAPITIS leitet sie den göttlichen Gnadenerlass nach unten zur Szene der Geburt Christi. Diese vertikale Bewegung betont somit ein spezifisches Narrativ der in der Geburt Christi vollzogenen Fleischwerdung Gottes. Die Erzählung wird nicht anhand der apokalyptisch-johannitischen Offenbarung entwickelt, sondern folgt eher der im Matthäus- und Lukas-Evangelium enthaltenen Weihnachtsgeschichte (Mt 1,18-25; Lk 1,26-28; 2,1-20). Hingegen werden auf dem horizontalen Arm des Kreuzes im SINISTRUM BRACIUM ein Kruzifix im Herzen, Christus im Limbus und die Porta Coeli gezeigt. Im DEXTRUM BRACCHIVM sind die Wiederauferstehung, die Himmelfahrt und ein zweiter Gottvater, unter dem ein Passus aus dem Matthäusevangelium steht (Mt 25, 34), zu sehen.

Giovanni Battista de“ Cavalieris Allegorie zeigt daher die Wirkung des Heiligen Geistes, wie sie sowohl mit dem christlichen Heilsversprechen im Kreuzes- und Messopfer als auch mit der Fleischwerdung Gottes im Zusammenhang steht. Damit folgt das Bildnarrativ der einzelnen Szenen einer ekklesiologischen Auslegung des Kreuzes- und Messopfers. Sie wird in der gewaltigen Architektur des Kreuzabsatzes des unteren Bildabschnitts betont. Die Inschrift, welche die Szene der Verkündigung mit der Geburt Christi verbindet und die sieben Tugenden als Relief zeigt, verweist auf eine CONVERSATIO IN TERRIS. Damit stellt die Bildlösung der Allegorie des Kreuzes nicht - wie im Stich des Typus Ecclesiae - eine Übertragung der himmlischen Heilsbotschaft in die irdische Heilserlangung dar. Vielmehr wird in Cavalieris Stich ein usus triplex des Kreuzes innerhalb der Ecclesia erläutert. Dieser dreifache Gebrauch des Kreuzes ist von den vier unteren Szenen aus dem Alten Testament im SIGNVM CRUCIS präfiguriert. Den Reliefblock mit den sieben Tugenden umrahmen zwei Figuren, die eine Verbindung zu den beiden horizontalen Armen des aufgestellten Kreu-

644 Pizzamano 2001, S. 30; Scorsetti 2002, S. 2, Nr. 71; Leuschner 2005, S 268; Gallori 2013, S. $238-265$. 
zes aufbauen. Die rechte Figur blickt in die Richtung Gottvaters, der das himmlischzeitlose Heilsversprechen verkündet. Dieses Heilsversprechen wird folglich im Kreuzesund Messopfer Christi ekklesiologische erfüllt. Die Szene des S. CRVCIS VSVS TRIPLEX IN ECCLESIA stellt im Zentrum den rituellen Akt der consecratio des Segensgestus dar und wird von zwei tondi eingerahmt. ${ }^{645}$ Die rechte Scheibe unterhalb der Engelsfigur zeigt ein Kreuz. Das Tondo unter der Ecclesia verweist mit seiner umrahmenden Inschrift (DIABOLI ET TENTATIONVM DEPVISIO) auf die Kraft des Kreuzes gegen die teuflische und dämonische Verführung. Cavalieri stellt somit in seiner Allegorie des Kreuzes ein Gleichgewicht zwischen den teuflischen Verführungen auf Erden und den himmlischen Kräften des Heilsversprechens dar. Das Heilsversprechen wird in der vita Christi, welche die Architektur des Kreuzes und damit auch den gesamten Bildaufbau des Stiches bestimmt, eingelöst.

Die beiden Stiche weisen unabhängig voneinander eine deutliche Korrespondenz mit der vom major poenitentiarius Stanislaus Hosius vertretenen Ekklesiologie auf, die der Ermländer Bischof in seinen frühen Schriften zwischen 1557 und 1558 festlegte. Damit kann Hosius aber nicht als eigentlicher Programmgestalter der beiden Stiche angenommen werden. Die sinnstiftende Programmgestaltung der Stiche Treters und Cavalieris spricht weitere Bereiche der Sakramentstheologie an. Allerdings wurde die Bedeutung dieser Stichserie noch nicht im Zusammenhang mit einer den Bedingungen des römischen Stadtraumes entsprechenden Vorstellung der pietas untersucht. ${ }^{646}$ Diese Übereinstimmung wird am deutlichsten in Cavalieris drittem und letztem Stich betont (Abb. 19c). Diesem Stich, der die Roma Sancta alle-

645 Gemäss den Auslegungen des Kardinalspönitentiars Stanislaus Hosius in seiner Widerlegung der Prolegomena des Johannes Brenz enthielt dieser dreifache usus eine innige Gemeinsamkeit mit der Trinität, in welcher er die pietas schlechthin inbegriffen sah. Vgl. hierzu Hosius, Verae, Christianae, Catholicaeque Doctrinae, S. 309: Immo vero Brenti omnis Evangelica disciplina, quin \& vera pietas omnis, hoc uno signo crucis quodamodò comprehenditur \& explicatur. Quod cum apud nos ne pueri quem ignorent, est ne verisimile te nescire Brenti? Sic apud nos matres puerulos instituunt, simulut inceperint qualem rationis usum habere: Posteaquam e somno fueris expergefactus, surgens $e$ lecto cruce te signa: Similiter facies cum iueris cubitum. Duces autem signum hoc a vertice capitis sive à fronte, ad vumbiculum usqu; simul cogitationem tuam ad Christum referes, qui de summo caelo egressus descendit in viscera matris, artque ex purissimis illius sanguinibus carnem nostram assumpsit. Deinde collocabis manum in sinistro brachio, \& duches ad dextrum, simul causam animo tecum repetes, quamobrem eo se demittere Dei filius dignatus fuerit, ut relinqueret domum suam, dimitteret haereditatem suam, daret dilectam animam suam in manus inimicorum suorum in cruce pro nobis moriens. Fecit enim haec, ut nos qui pro meritis nostris cum haedis a finistris oramus collocandi, trasferret ad dexteram inter oves suas, ubi vocem illam desiderata audire nobis liceret [...] Vides quanta fidei nostrae mysteria unica hac signandi nos cruce forma nobis Apostoli tradiderint? [...] Hic enim incarnatio, hic passio Christi, his causa passionis, hic extremum illud iudicium, et spes nostrae vocationis, hic mysterium Trinitatis, per quam redempti sumus, unica signatione crucis exprimitur. Zur Beteiligung des Jesuiten Canisius an der Drucklegung in Köln 1558 vgl. Hosius, Opera omnia, II, S. 892-895; Deuschle 2006, S. 95-96.

646 Chrzanowski 1978; Jurkowlaniec 2012, S. 135. 
gorisch darstellt, räumt Hosius in seinem Briefschreiben an Borromeo den wichtigsten Stellenwert in der Gesamtserie ein. In Cavalieris Bildausführung wird eine allegorische Vorstellung der pietas gezeigt, die im Pilgerzeremoniell verwirklicht wird. Das nun im Rom des anno santo selbst eingelöste Heilsversprechen Christi kann auf der Grundlage eines ebenfalls 1575 gedruckten Traktates des polnischen Kanonikers Tomasz Treter interpretiert werden. In seiner Roma Santa stellt Treter ein Gleichnis zwischen der Ecclesia und der Allegorie der Roma her. Der Traktat ist ein Dialog zwischen einem Römer und einem Pilger, der die Ewige Stadt anlässlich des Jubeljahres besucht. Der Romano beantwortet die Fragen, welche der Pilger in Bezug auf die in Cavalieris Blatt dargestellten Szenen und Personifikationen stellt. Auf die Frage des Pilgers, wen die Figur in der Bildmitte von Cavalieris Stich darstelle, antwortet der Römer folgendermassen:

Questa rappresenta la figura della Città di Roma, la quale da ciascuno è dimandata capo del mondo, \& ottenne già in quella più antica età l'imperio di tutto il mondo, \& hora si vede, che la Maestà di quell'Imperio si è mutata in una piu eccellente, e perpetua gloria; e questa gloria è tanto più nobile di quella maestà di Roma anticamente quanto è piu nobile l'anima, giudico d'ognuno, del corpo. Imperoche anticamente, signoreggiò Roma solamente sopra i corpi humani, e sopra le provincie terrene [...] ma hora tiene Roma l'imperio sopra l'anime, \& è ancora partecipe de sommo bene, \& è la sede del Vicario di Christo, al quale è stata data da Iddio la potestà di legare, e di sciorre l'anime. ${ }^{647}$

Giovanni Battista de' Cavalieris Stich der Roma Sancta ist auch bildsprachlich wichtig, da der Kupferstecher das Heilsgeschehen Christi bildrhetorisch in eine allegorische Bildsprache umwandelt. Rom wird dadurch mit der Ecclesia gleichgesetzt.

Die Stadt gleicht somit einer Kirche, in welcher sich das Heilsversprechen Christi gegenüber den zahlreichen Pilgern rituell vollzieht. Die gesamte Stichserie, die dem Kardinal-Pönitentiar Stanislaus Hosius gewidmet wurde, entwickelt mit ihrem Bildnarrativ eine Überführung des Typus Ecclesiae in die allegorische Vorstellung der Roma Santa. Rom wird damit zum Sinnbild einer alle Sakramente umfassenden Ecclesia stilisiert, woraus sich dann der göttliche Sünden- und Gnadenerlass im verzeitlichten Heilsgeschehen des anno santo ableiten lässt. Das sich heute im Department of Prints and Drawings des British Museum befindende Blatt Cavalieris folgt in seiner Komposition nicht mehr länger einer noch in den beiden zuvor besprochenen Stichen beobachtbaren Bildarchitektur. In diesem letzten Stich leitet der Kupferstecher Cavalieri aus der zentralen Hauptfigur der Allegorie Roms und dem diese Figur einrahmenden Schriftzug den dynamischen Fluss der göttlichen Heiligsprechung (sanctificatio) ab. Derselbe Schriftzug teilt Cavalieris Stich in zwei Teile ein. Der Passus Fluminis impetus laetificat civitatem Dei/ Sanctificavit tabernaculum suum Altissimus (Ps 45, 5) schafft dabei eine Durchlässigkeit zwischen Bildzentrum und -rand. Die Zentralachse des Blattes hingegen baut mit der Taube des Heiligen Geistes die gleiche Verbindung zwischen einer

647 Treter, Roma Santa, c. B1r. 
zeitlos-himmlischen Sphäre göttlicher benignitas und der auf Erden verzeitlichten sanctificatio auf wie in der Allegorie des Kreuzes und im Stich des Typus Ecclesiae Catholicae. Die vier Patriarchalbasiliken Roms fungieren als Grenzen des Heilsraumes und entsprechen den bereits im Kurienzeremoniell angetroffenen limina Apostolorum. Der Titel von Cavalieris Blatt, Benedices coronae anni benignitatis tuae (Ps 64, 12), verweist auf die der Roma Sancta verliehene himmlische coronae. Die Tiara und die dem römischen Apostelfürsten Petrus überreichten Schlüssel repräsentieren die päpstlichen Insignien der spirituellen und temporalen potestas. Zwischen diesen beiden coronae ist ein Kreuz eingefügt. Dieses steht Tomas Treters Roma Santa zufolge nicht nur für den Triumph Christi über den Teufel, sondern ist auch als Zeichen des imperialen Triumphes Kaiser Konstantins d. Gr. über „den Tyrannen Maxentius“ zu verstehen. ${ }^{648}$

Die drei coronae, die Gottvater vom Himmel aus überreicht, sind somit als Spolien des Sieges Christi über den Teufel zu deuten. Der Kelch und die Hostie, welche die Figur der Roma Sancta mit ihrer rechten Hand emporhebt, verweisen daher auf Spolien des Triumphes der Ecclesia über den Aberglauben (superstitio):

\begin{abstract}
Sappiate, che sant'Agostino cosi ha lasciato scritto, Se i falsi Dij non havesser conosciuto che il tempio, il sacerdote, il sacrifitio si dovessero al unico, e vero Dio, mai non harebbero volsuto tal cose da coloro, iquali li adorano, e li quali son da detti Demoni ingannati. Per questa cagione volendo Christo Salvatore nostro mandar per terra questa abominevol superbia de Demoni con tutta la superstitione cosi pernitiosa de popoli, egli ancora ha voluto ordinar il sacrificio del Santissimo suo corpo, e sangue in questo culto che a lui propriamente si conviene accioche fosse ne li homini veramente adorato. Onda la chiesa Romana spenta a fatto la Idolatria, ricevendo questo sacrificio dalle mani de gli istessi Apostoli, \& cosi per una longa successione de i Vescovi e de sacerdoti l'ha sempre mai con gran veneratione conservato cosi puro e perfetto, che ella sia stata meritamente dall'istesso Christo a tutti proposta conduttrice e maestra, e come un essempio qual tutti imitassero non solo in questo, ma in tutte le altre cose de la nostra religione. ${ }^{649}$
\end{abstract}

648 Ibid., c. B1v-B2v: „Non sapete voi coloro li quali son sottoposti a Principi terreni pongono ne piu eminenti luoghi il piu delle volte le loro armi, \& imprese? Et questo sanno accio coloro, li quali son da loro come suoi patroni amati, siano a tutto'l mondo manifesti: cosi parimente trovandosi il Demonio forte e ben armato, e per il pomo di Adamo vincitore, venne poi Christo piu forte di lui, e lo vinse nel arbore della Croce, e lo spoglio di tutte le sue armi, nelle quali tanto si confidava. Però doppo che Roma cominciò ad ubidir a questo piu forte Christo, ha sempre mai giudicato, che questo salutifero segno del suo celeste Re si dovesse portarle inanzi a se, \& ancora si dovesse con grandissimo honore riverirle. Non havete voi letto o almeno udito com'io penso, che la Croce apparve dal Cielo a quel Costantino Imperatore dimandato per la grandezza delle cose fatte da lui Magno, e che in detta croce per vitù certamente di Dio superò Massentio Tiranno, il quale si sforzava di opprimere la libertà del Popolo Romano. Per dimostrarsi adunque Roma grata e di si gran beneficio ricordevole [...].“ Vgl. Thurston 1900, S. 260-261; Pastor 1893-1933, Bd. 9, S. 154-155; Fagiolo/Madonna 1985, S. 266; Malesevic 2015, S. 53-54.

649 Treter, Roma Santa, c. B2r. 
Im dritten und letzten Blatt der Stichserie Treters und Cavalieris wird ferner eine spezifische Eintracht zwischen der Figur der Roma Sancta, die sinnbildlich die Ecclesia Romana repräsentiert, und dem Kreuzes- und Messopfer Christi vorgestellt. Diese Eintracht stimmt mit der theologischen Bedeutung der Transsubstantiationslehre überein. Im Wesenswandel des Leibes und Blutes Christi wird der Ecclesia das sacrificium Christi als ihr dauerhaft wohlverdientes (meritevole) Geschenk Gottes überreicht. Dieses wohlverdiente Geschenk des Kreuzes- und Messopfers ist in den die Roma Sancta umgebenden Vignetten der caritas hervorgehoben. Dieser Stich Cavalieris betont daher den rituellen Vollzug des göttlichen Sünden- und Gnadenerlasses im Augenblick des anno santo und baut damit bewusst ein Spannungsverhältnis zu der in der ambrosianischen Liturgie vertretenen Grundidee der Kirche als „Braut Christi“ (Ecclesia sponsae Christi) auf. Obwohl sich das Kurienzeremoniell zum anno santo derselben Grundidee der Identität zwischen Kirche und Christus verschrieben hatte, wird in Cavalieris Stich diese tertullianische Maxime auf den zelebrierenden Priester übertragen. Er setzt die Insignien des sacrificium in seinem Vollzug der zwölf leiblichen und geistlichen Werke der caritas ein und verkörpert selbst das matrimonium zwischen Ecclesia und Christus. Erst in diesem priesterlichen Akt der caritas, in welchem die pietas enthalten ist, vollzieht sich das himmlischgöttliche Geschenk der Gnade. In diesem Gnadengeschenk wird auch gleichzeitig das im Kreuzes- und Messopfer Christi enthaltene Heilsversprechen erneuert. Das römische Verständnis des rituellen Vollzugs des göttlichen Gnadenerlasses spricht daher nicht mehr länger das sich in der Ecclesia verwirklichende mysterium der Fleischwerdung Gottes, wie es im ambrosianischen Ritus von Borromeos Diözesanverwaltung Mailands der Fall war, an. Im Zentrum des verzeitlichten Gnadenerlasses steht nun das fromme Priestertum (sacerdotium), aus welchem sich die Kraft des christlichen Heilsversprechens sichtbar entfaltet. ${ }^{650}$ Der römische Stadtraum wurde also mittels der bereits besprochenen Theologie der Genugtuung einem Wandel unterzogen, durch den der rituelle Vollzug der caritas seitens des Priestertums und die Verwaltung der Sakramente einen Heilsraum entstehen liessen. In diesem Heilsraum liess sich die zeitlos göttliche Heilsbotschaft in ein fleischgewordenes christliches Heilsversprechen verzeitlichen. Diese Umwandlung der urbanen Topographie Roms in eine sinnlich fassbare Topologie des christlichen Heilsgeschehens war allerdings nicht allein von den Eingriffen der Kurie in den Stadtraum geprägt, sondern leitete sich aus einem erneuerten Bewusstsein der verdienten Heilserlangung ab. Im Augenblick des göttlichen Gnadenerlasses wird auch ein Gnadenschatz auf Erden ausgeschüttet. Dieser theologischen Idee des anno santo lag eine mittelalterliche Schatztheologie zu Grunde, welcher sich der nächste Abschnitt widmen wird.

650 Die am 15. Oktober 1574 erlassene Papstbulle Quae publice utilia nahm diesen Grundgedanken des frommen Priestertums vorweg: Bull. dipl. rom., VIII, S. 88-95; BAV, Urb. lat. 1044, f. 311r-313r. 